\title{
Moisture and dynamical interactions maintaining decoupled Arctic mixed-phase stratocumulus in the presence of a humidity inversion
}

\author{
A. Solomon ${ }^{1,2}$, M. D. Shupe ${ }^{1,2}$, P. O. G. Persson ${ }^{1,2}$, and H. Morrison ${ }^{3}$ \\ ${ }^{1}$ CIRES, University of Colorado, Boulder, Colorado, USA \\ ${ }^{2}$ Earth System Research Laboratory/NOAA, Boulder Colorado, USA \\ ${ }^{3} \mathrm{MMM} / \mathrm{NESL} / \mathrm{NCAR}$, Boulder, Colorado, USA
}

Received: 20 April 2011 - Published in Atmos. Chem. Phys. Discuss.: 4 May 2011

Revised: 17 September 2011 - Accepted: 20 September 2011 - Published: 7 October 2011

\begin{abstract}
Observations suggest that processes maintaining subtropical and Arctic stratocumulus differ, due to the different environments in which they occur. For example, specific humidity inversions (specific humidity increasing with height) are frequently observed to occur near cloud top coincident with temperature inversions in the Arctic, while they do not occur in the subtropics. In this study we use nested LES simulations of decoupled Arctic Mixed-Phase Stratocumulus (AMPS) clouds observed during the DOE Atmospheric Radiation Measurement Program's Indirect and SemiDirect Aerosol Campaign (ISDAC) to analyze budgets of water components, potential temperature, and turbulent kinetic energy. These analyses quantify the processes that maintain decoupled AMPS, including the role of humidity inversions. Key structural features include a shallow upper entrainment zone at cloud top that is located within the temperature and humidity inversions, a mixed layer driven by cloud-top cooling that extends from the base of the upper entrainment zone to below cloud base, and a lower entrainment zone at the base of the mixed layer. The surface layer below the lower entrainment zone is decoupled from the cloud mixed-layer system. Budget results show that cloud liquid water is maintained in the upper entrainment zone near cloud top (within a temperature and humidity inversion) due to a down gradient transport of water vapor by turbulent fluxes into the cloud layer from above and direct condensation forced by radiative cooling. Liquid water is generated in the updraft portions of the mixed-layer eddies below cloud top by buoyant destabilization. These processes cause at least $20 \%$ of the cloud liquid water to extend into the inversion. The redistribution of water vapor from the top of the humid-
\end{abstract}

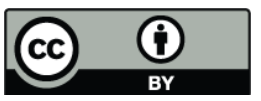

Correspondence to: A. Solomon (amy.solomon@noaa.gov) ity inversion to its base maintains the cloud layer, while the mixed layer-entrainment zone system is continually losing total water. In this decoupled system, the humidity inversion is the only source of water vapor for the cloud system, since water vapor from the surface layer is not efficiently transported into the mixed layer. Sedimentation of ice is the dominant sink of moisture from the mixed layer.

\section{Introduction}

Arctic mixed-phase stratocumulus (AMPS) are observed to occur approximately $45 \%$ of the time on the North Slope of Alaska, with a significant increase in occurrence during spring and fall transition seasons (Shupe, 2011). Due to the presence of liquid water in these clouds, they play an important role in determining the structure of the Arctic atmospheric boundary layer (ABL) and magnitudes of surface energy budget terms. For example, Morrison and Pinto (2006) demonstrated that, in mesoscale simulations of a springtime Surface Heat Budget of the Arctic Ocean (SHEBA) case study in the Beaufort Sea area, it is necessary to adequately simulate AMPS to produce well-mixed ABLs. In addition, since cloud liquid water causes an increase in downwelling longwave radiation and a decrease in incoming shortwave radiation, inadequate simulations of Arctic clouds cause significant errors in the modeled surface energy budget (e.g., Curry et al., 2000; Solomon et al., 2009).

AMPS are typically observed to persist for days in both spring, when the Arctic Ocean is essentially ice covered, and fall, when the open ocean produces relatively large fluxes of heat and moisture into the atmospheric boundary layer (see Shupe et al., 2006; Shupe, 2011). The persistence of AMPS under both strong and weak surface forcing conditions suggests that other mechanisms also contribute to the

Published by Copernicus Publications on behalf of the European Geosciences Union. 
maintenance of these clouds, and that the relative contributions by these mechanisms may differ from spring to fall. This idea is supported by mesoscale model simulations of AMPS observed during the fall Mixed-Phase Arctic Cloud Experiment (MPACE, Morrison et al., 2008), where liquid water paths (LWPs) in AMPS during periods of open water were found to be less sensitive to changes in cloud condensation nuclei $(\mathrm{CCN})$ than for clouds in modeling studies over sea ice (e.g., Pinto, 1998; Harrington et al., 1999; Jiang et al., 2001). In addition, Morrison et al. (2008) found that changes in LWP did not significantly impact large-scale circulation, in contrast to modeling studies of ice-covered conditions during SHEBA (Morrison and Pinto, 2006). However, AMPS forcing mechanisms involving cloud-top processes are likely relatively insensitive to seasonal differences of surface characteristics. In cases with and without open water, Pinto (1998) observed entrainment near cloud top by turbulent mixing (hereafter referred to as the upper entrainment zone), and downdrafts in the boundary layer that were forced by cloud top radiative cooling.

AMPS have not been studied as extensively as stratocumuli that occur in regions of the descending branch of the Hadley circulation over relatively cool subtropical oceans (Sc) (e.g., Norris, 1998). Observations indicate that the processes that maintain subtropical and Arctic stratocumulus differ due to the different environments in which they occur. For example, specific humidity inversions (specific humidity increasing with height) are frequently observed to occur coincident with temperature inversions in the Arctic (e.g., Curry et al., 1996; Tjernström et al., 2004; Sedlar and Tjernström, 2009). In a recent study, Sedlar et al. (2011) surveyed data from SHEBA, the Arctic Summer Cloud Ocean Study (ASCOS) in the central Arctic Basin, and at Barrow, Alaska, to find that specific humidity inversions occurred $75-80 \%$ of the time when low-level clouds were present. In addition, this study found a significant relationship between the existence of specific humidity inversions and AMPS that extended into the temperature inversion, highlighting the difference between AMPS and subtropical stratocumulus where the entrainment of dry air aloft prevents cloud liquid water from forming in the temperature inversion. Other important ways in which AMPS differ from warm Sc include more effective cloud top radiative cooling because of the cold, dry overlying Arctic free troposphere, and vapor diffusion onto ice (Bergeron process), which acts as a potential large sink of water vapor even when there is limited liquid water. In contrast, in warm Sc drizzle grows by collision-coalescence of droplets, so as liquid water decreases, drizzle production shuts off (see Morrison et al. (2011) for a detailed discussion of this point).

To highlight differences between Arctic and subtropical stratocumulus, we first plot fields from a sounding taken during the springtime over Graciosa Island in the Azores of a single layer stratocumulus deck (Fig. 1). This subtropical sounding indicates an inversion of $6 \mathrm{~K}$ at $1.6-1.8 \mathrm{~km}$. A de-
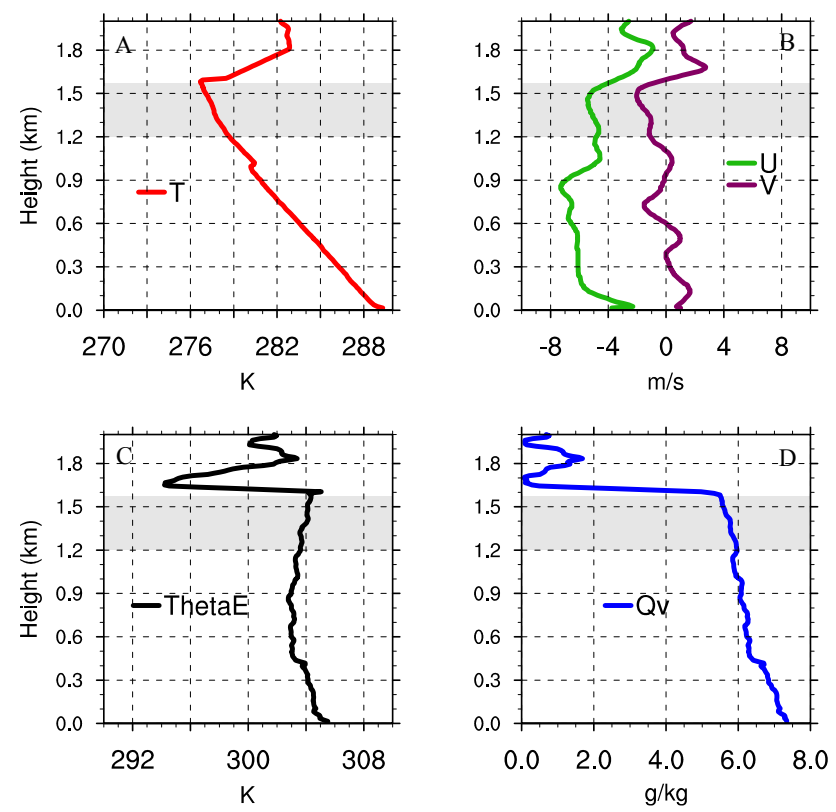

Fig. 1. Sounding of decoupled subtropical stratocumulus at 23:27 Z 5 May 2009 over Graciosa Island, Azores, Portugal $\left(39.13^{\circ} \mathrm{N}\right.$, $28.94^{\circ} \mathrm{W}$ ). (A) Temperature, in units of K. (B) Horizontal winds, in units of $\mathrm{m} \mathrm{s}^{-1}$. (C) Equivalent potential temperature, in units of K. (D) Specific humidity, in units of $\mathrm{g} \mathrm{kg}^{-1}$. Gray shading marks the cloud layer.

crease in specific humidity with height causes equivalent potential temperature $\left(\theta_{\mathrm{e}}\right)$ to also decrease with height, most significantly within the inversion above cloud top. A sharp decrease in humidity causes the inversion to be potentially unstable by the Cloud Top Entrainment Instability (CTEI) criteria (e.g., Randall, 1980; Deardorff, 1980). Longwave cooling at cloud top causes the sharp, strong inversion, capping the cloud layer, and limits entrainment of warm, dry air from above (e.g., Nichols, 1984). The weak inversion at $1 \mathrm{~km}$ indicates that the cloud layer is decoupled from the surface. In addition, horizontal winds indicate wind shear near cloud top and divergence that is approximately constant with height within the mixed layer that balances large-scale subsidence above cloud top (not shown). These conditions are typical of marine stratocumulus-topped boundary layers. For example, see composites in Albrecht et al. (1995) and Norris (1998).

There have been many studies of decoupling in subtropical Sc. The decoupling of warm moist surface air from the cloud layer in a subtropical sounding is due to cloud layer warming by solar absorption, which limits the extent of turbulent mixing within the cloud layer generated by longwave cooling at cloud top (e.g., Nichols, 1984). However, decoupling also occurs by evaporation of drizzle below the cloud (e.g., Brost et al., 1982) and advection of the Sc cloud deck over warmer SSTs (e.g., Wyant et al., 1997). Decoupling in subtropical Sc 

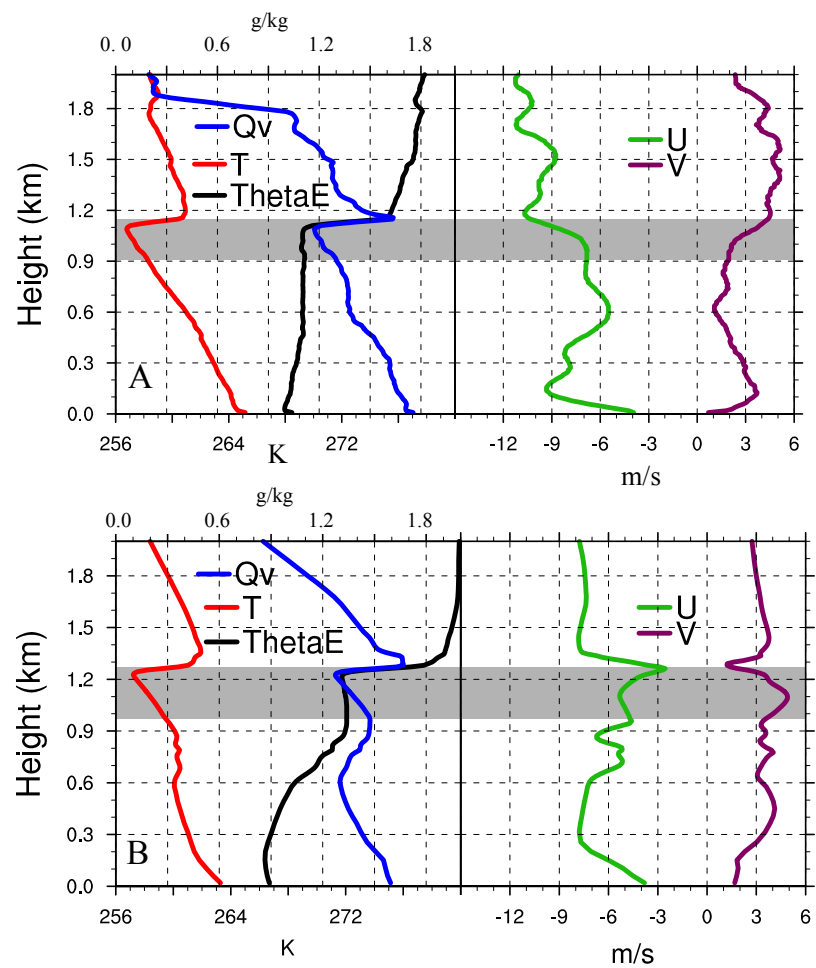

Fig. 2. Soundings of mid-day decoupled stratocumulus at Barrow, Alaska. (A) Measured 17:34Z 8 April 2008 at (71.33 $\left.\mathrm{N}, 156.61^{\circ} \mathrm{W}\right)$. (B) $50 \mathrm{~m}$ LES simulation $20 \mathrm{Z} 8$ April 2008 at $\left(71.33^{\circ} \mathrm{N}, 156.91^{\circ} \mathrm{W}\right.$; red star in Fig. 6). Gray shading marks the extent of the cloud layer.

can cause a cloud to evaporate unless cumulus clouds form below the subcloud mixed layer and transport moisture upward to the cloud layer (Nicholls, 1984). Idealized model studies have been used to examine the impact of precipitation on these clouds. Sedimentation causes a decrease in cloud water in the upper entrainment zone, decreasing longwave cooling and turbulent mixing of dry warm air aloft into the cloud layer, ultimately increasing the liquid water path (e.g., Ackerman et al., 2004; Bretherton et al., 2007). Drizzle stabilizes the boundary layer by latent heating in the cloud layer and evaporation below cloud base, potentially depleting the boundary layer of water if drizzle is strong enough to reach the surface (e.g., Stevens et al., 1998).

In contrast to the warm $\mathrm{Sc}$, a sounding containing a singlelayer Arctic mixed-phase stratocumulus is plotted in Fig. 2a. This sounding was taken in spring when the Arctic Ocean was essentially ice-covered. However, satellite images show regions of open water providing a possible source of lowlevel moisture. A detailed discussion of this Arctic case study is provided in Sect. 2 . The sounding indicates a surface temperature of $\sim-8{ }^{\circ} \mathrm{C}$ and surface specific humidity of $\sim 1.7 \mathrm{~g} \mathrm{~kg}^{-1}$. The $\theta_{\mathrm{e}}$ profile monotonically increases with height up to $500 \mathrm{~m}$ where the slope changes, indicating a decoupling between a stable surface layer and a cloud-driven mixed layer (the layer between $0.5-1.1 \mathrm{~km}$, which contains most of the cloud layer and extends $400 \mathrm{~m}$ below the cloud). A temperature inversion of $4 \mathrm{~K}$ at $1.1 \mathrm{~km}$ makes the cloud top stable relative to the overlying atmosphere and defines the lower boundary of an upper entrainment zone that is approximately $50 \mathrm{~m}$ in depth. We have estimated the boundaries of entrainment zones by changes in the $\theta_{\mathrm{e}}$ slope, which yields similar results to assuming the top of the entrainment zone is located at the top of a region of negative buoyancy (see Deardorff (1979) for a discussion on this point). Specific humidity decreases with height from the surface to the base of the temperature inversion, where there is a coincident humidity inversion that suggests horizontal advection of warm, moist air aloft. Specific humidity at the top of the inversion is nearly equal to its value at the surface. Horizontal winds indicate significant shear at the inversion (similar to subtropical Sc, the base of the mixed layer, and near the surface. Winds are relatively weak and uniform within the mixed layer.

In this study we examine many details of AMPS using results from nested LES simulations during the DOE Atmospheric Radiation Measurement (ARM) Program's Indirect and SemiDirect Aerosol Campaign (ISDAC, McFarquhar et al., 2011). We specifically focus on structures and processes that distinguish AMPS from subtropical Sc, such as the role that a cloud top humidity inversion plays in cloud maintenance.

In Sect. 2 we outline observations of the environmental conditions and cloud properties during ISDAC. In Sect. 3 we describe the model and experiment design. Model results are compared with retrievals and soundings taken at Barrow, Alaska, in Sect. 4. In Sect. 5 we present budgets of cloud water $\left(q_{\mathrm{c}}\right)$, cloud ice $\left(q_{\mathrm{i}}\right)$, water vapor $\left(q_{\mathrm{v}}\right)$, total water $\left(q_{\mathrm{t}}\right)$, potential temperature $(\theta)$, and turbulent kinetic energy (TKE) to quantify the processes that maintain the AMPS. Finally, we discuss our findings relative to previous studies of Arctic and subtropical stratocumulus clouds in Sect. 6.

\section{Observations}

\subsection{Synoptic-scale features}

In April 2008, ISDAC was conducted to measure mixedphase clouds in both clean and polluted environments over the North Slope of Alaska and adjacent Arctic Ocean (see McFarquhar et al., 2011). Two "golden days" were identified where persistent, single-layer mixed-phase stratocumulus were extensively observed by aircraft and ground-based sensors. This study focuses on the 8 April 2008 case. During this time, the Beaufort Sea was generally ice covered and roll clouds were not observed, in contrast to fall conditions in the area (for example, see MPACE case study of Solomon et al., 2009). However, visible images taken on 8 April by the Terra satellite indicate that significant areas of open water east of Barrow may have impacted cloud 

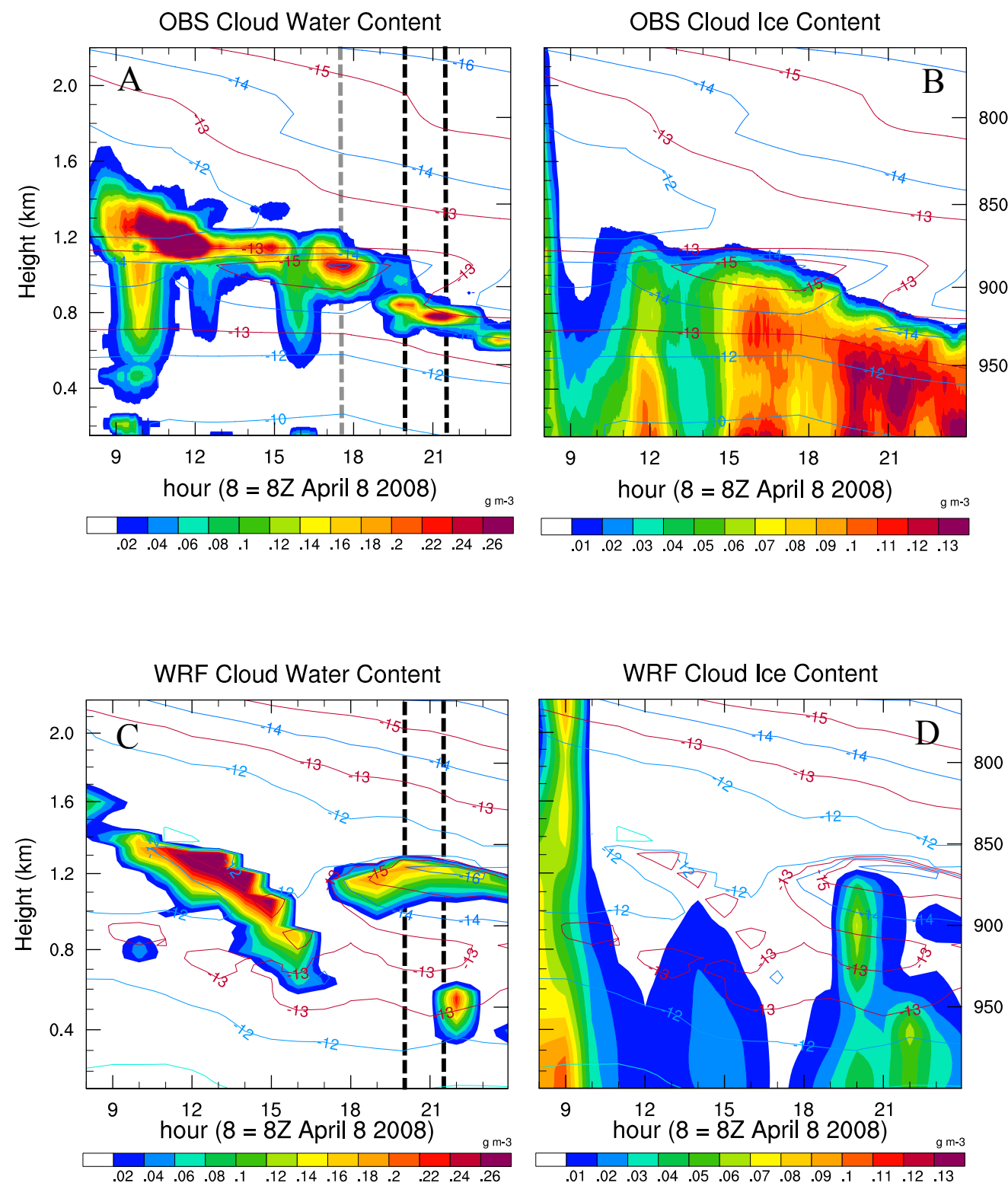

Fig. 3. Observationally retrieved one-hour running mean cloud liquid (A) and ice (B) water content, in $\mathrm{g} \mathrm{m}^{-3}$, at Barrow, Alaska from 8-24 Z 8 April 2008 (color). Hourly output of liquid water $(\mathbf{C})$ and ice (D) from WRF $1 \mathrm{~km}$ nest. Temperature isopleths $\left({ }^{\circ} \mathrm{C}\right)$ are interpolated from soundings at 4:22 Z 8 April 2008, 17:34 Z 8 April 2008, 5:32 Z 9 April 2008 . Note $-13^{\circ} \mathrm{C}$ and $-15^{\circ} \mathrm{C}$ contours are red to highlight inversions. Black dashed lines in $(\mathbf{A})$ and $(\mathbf{C})$ indicate the validation period. The gray dashed line in $(\mathbf{A})$ indicates the time of the sounding.

formation and boundary layer structure during this period. Two soundings were made at Barrow on the 8th at $4: 22 \mathrm{Z}$ and 17:34Z. The first sounding shows that the initial wind direction was northerly at the surface, gradually veering to easterly at $1.4 \mathrm{~km}$ and thereby indicating warm air advection. By the second sounding (see Fig. 2a), occurring after a marked surface wind shift at 08:00 UTC, winds were east-southeasterly throughout the lowest $2.0 \mathrm{~km}$ indicating no thermal advection as a northward-moving high pressure system was located NE of Barrow (McFarquhar et al., 2011).

\subsection{Cloud and boundary layer properties}

At Barrow, measurements taken with a ground-based vertically pointing $35-\mathrm{GHz}$ cloud radar, a micropulse cloud lidar, and a dual-channel microwave radiometer were combined (Shupe, 2007) to reveal multi-layered mixed-phase and ice clouds extending from the surface to $3 \mathrm{~km}$ that persisted from 0Z-8Z until a warm frontal passage when the cloud top descended to $1 \mathrm{~km}$ (Fig. 3b). At 17:34 Z, the temperature profile shows a sharp $(\sim 4 \mathrm{~K})$ inversion at $\sim 1 \mathrm{~km}$ (Figs. 2a, 3a), with 
cloud top extending up into the inversion by approximately $100 \mathrm{~m}$ (Fig. 3a). The AMPS persisted until $12 \mathrm{Z} 9$ April with cloud top slowly descending from $1 \mathrm{~km}$ to $500 \mathrm{~m}$ over this period. The large scale forcing for our model simulation (that is applied at the lateral boundaries of the $25 \mathrm{~km}$ nest) has a time delay of approximately two hours relative to observations. Therefore, the cloud that was observed to start descending at $18 \mathrm{Z}$ at Barrow begins to descend in the model simulation at 20Z. Ice precipitated from the base of the AMPS, but only trace precipitation was observed at the surface by the US. Climate Reference Network gauge near Barrow. Indications of a lower secondary cloud layer were observed at 10, 12, and $16 \mathrm{Z}$. The sounding at 17:34 Z (Fig. 2a) indicates that the surface and primary cloud layer were decoupled, with a well-mixed layer within and below the cloud (static stabilities close to neutral, $\partial \theta_{\mathrm{e}} / \partial z \cong \mathrm{g} 0$ ) and a stable layer below (static stabilities greater than $2 \mathrm{~K} / \mathrm{km}$ below $500 \mathrm{~m}$ ). Water vapor mixing ratios decreased from $1.7 \mathrm{~g} \mathrm{~kg}^{-1}$ at the surface to $1.2 \mathrm{~g} \mathrm{~kg}^{-1}$ at cloud top, above which a secondary maximum of $1.6 \mathrm{~g} \mathrm{~kg}^{-1}$ was observed.

Microphysical properties for these clouds were also derived from ground-based remote sensors. First, a cloud phase classification (Shupe, 2007) was used to determine the vertical distribution of cloud phase. Cloud ice water content (Fig. 3b), and its vertical integral the ice water path (IWP), were derived from cloud radar reflectivity measurements with an uncertainty of up to a factor of two (Shupe et al., 2006). Cloud liquid water path (LWP) was derived from dual-channel microwave radiometer measurements with an uncertainty of $20-30 \mathrm{~g} \mathrm{~m}^{-2}$ (Turner et al., 2007), while the cloud water (Fig. 3a) was distributed vertically with a scaled, adiabatic calculation using observed cloud boundaries and interpolated radiosonde measurements. Finally, in-cloud vertical air velocity $(w)$ was derived from cloud radar Doppler spectra (Shupe et al., 2008a). Between 12-24 Z, IWP exceeded LWP and liquid fraction (LF, ratio of LWP to LWP + IWP) was generally below 0.4. IWP generally exceeded $60 \mathrm{~g} \mathrm{~m}^{-2}$ and LWP ranged between 20$100 \mathrm{~g} \mathrm{~m}^{-2}$. IWP and LWP were significantly correlated over $2 \mathrm{~min}$ to $1 \mathrm{~h}$ averaging periods, which is meaningful because of the vertically coherent nature of the ice content shafts within the cloud mixed layer where the ice content is greatest, (Fig. 2b). Unlike AMPS observed during fall at Barrow, IWP was not depleted in downdrafts (see Shupe et al., 2008b). Cloud-averaged $w$, LWP, and IWP had maximum correlations at zero lag (results not shown).

\section{Model setup and experiment design}

\subsection{WRF V3.1}

The Weather Research Forecast (WRF) V3.1 model (Skamarock et al., 2008) is used for this study with five two-way nested grids with horizontal grid spacings of $25 \mathrm{~km}, 5 \mathrm{~km}$,
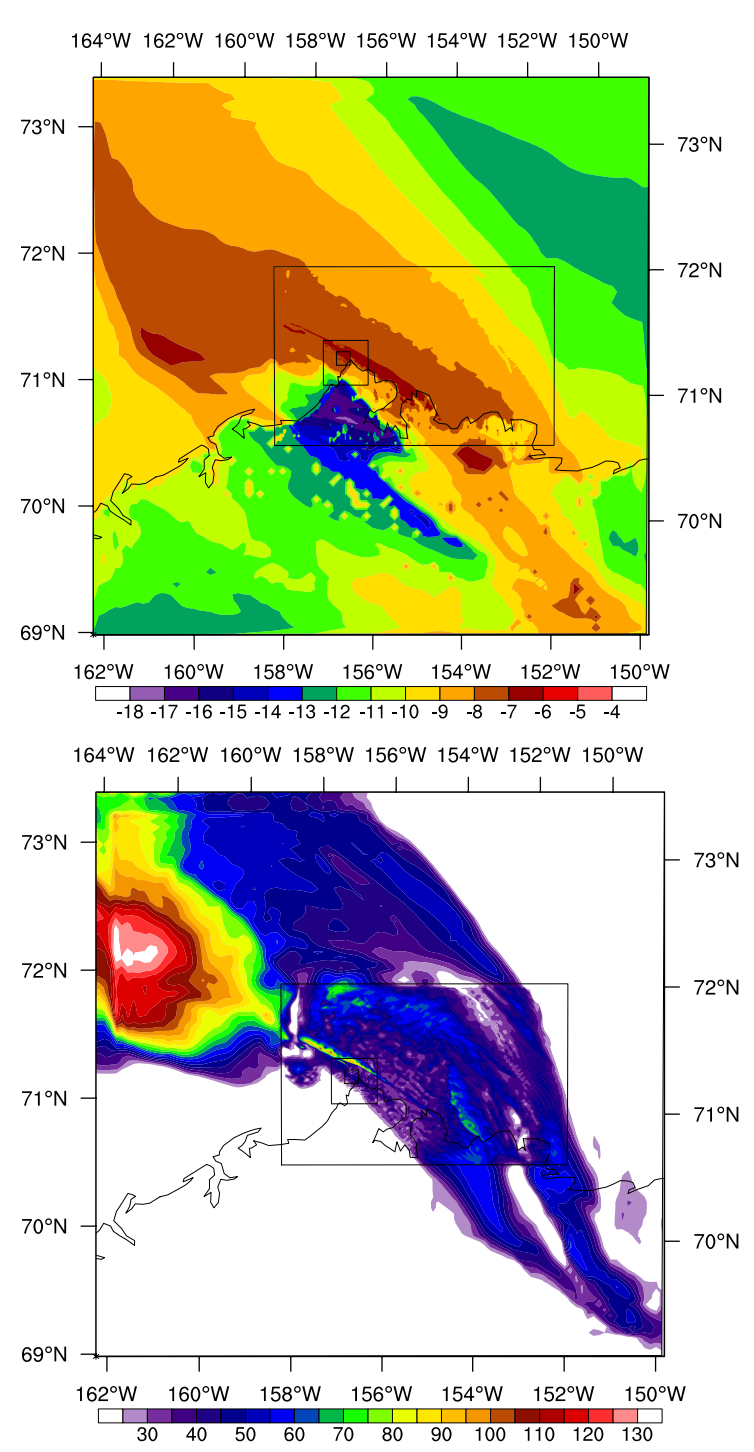

Fig. 4. Surface skin temperature (top) and liquid water path (bottom), in units of ${ }^{\circ} \mathrm{C}$ and $\mathrm{g} \mathrm{m}^{-2}$, respectively, at $20 \mathrm{Z} 8$ April 2008 for the $50 \mathrm{~m}, 200 \mathrm{~m}, 1 \mathrm{~km}$ and $5 \mathrm{~km}$ nests. Barrow, Alaska is located directly to the east of the $50 \mathrm{~m}$ nest southeast corner.

$1 \mathrm{~km}, 200 \mathrm{~m}$, and $50 \mathrm{~m}$ (Fig. 4). The $50 \mathrm{~m}$ nest has $241 \times 241$ horizontal gridpoints $(12 \mathrm{~km} \times 12 \mathrm{~km})$ and is placed just to the northwest of Barrow. The boundary layer is well resolved in the vertical by including 85 pressure levels below $800 \mathrm{hPa}$. In order to better resolve entrainment and mixing in the mixed-layer and upper entrainment zone, the vertical grid spacing $(\Delta z)$ is $16 \mathrm{~m}$ in the cloud-driven mixed layer $(0.6-1.5 \mathrm{~km})$ and $8 \mathrm{~m}$ in the upper entrainment zone $(1.2-1.4 \mathrm{~km})$. Below $0.6 \mathrm{~km}$ and above $1.5 \mathrm{~km} \Delta z=50 \mathrm{~m}$. Second order diffusion with a 1.5 order TKE prediction scheme is used to parameterize subgrid turbulence in the $1 \mathrm{~km}, 200 \mathrm{~m}$ and $50 \mathrm{~m}$ nests. The model is forced with lateral and surface boundary conditions from the European Centre 
Table 1. Packages used in WRF model setup.

\begin{tabular}{ll}
\hline Radiation package & $\begin{array}{l}\text { National Center for Atmospheric Research Community } \\
\text { Atmospheric Model longwave and shortwave radiation package. } \\
\text { The longwave code allows for interactions with resolved clouds and cloud fractions Collins et al. (2004). }\end{array}$ \\
\hline Surface layer physics package & $\begin{array}{l}\text { Monin-Obukhov with Carlson-Boland viscous sub-layer and standard similarity } \\
\text { functions following Paulson (1970) and Dyer and Hicks (1970). Surface exchange } \\
\text { coefficients for heat, moisture, and momentum computed following Webb (1970). } \\
\text { Four stability regimes are defined following Zhang and Anthes (1982). }\end{array}$ \\
\hline Land surface package & $\begin{array}{l}\text { Noah Land Surface Model; the unified NCEP/NCAR/AFWA scheme with soil temperature } \\
\text { and moisture in four layers, fractional snow cover and frozen soil physics Chen and Dudhia (2001). }\end{array}$ \\
\hline Planetary boundary & $\begin{array}{l}\text { Yonsei University scheme (non-local-K scheme with explicit entrainment layer } \\
\text { and parabolic K profile in unstable mixed layers) } \\
\text { in 5 and 25 km grids Hong et al. (2006). }\end{array}$ \\
\hline Microphysics package & $\begin{array}{l}\text { Morrison two-moment scheme including prognostic cloud droplets, cloud } \\
\text { ice, rain, snow, and graupel/hail Morrison et al. (2009). }\end{array}$ \\
\hline
\end{tabular}

for Medium-Range Weather Forecasts' (ECMWF) 4X daily, T255 ERA-Interim dataset. The model is spun-up by integrating from 00:00 UTC 8 April to 12ZUTC 8 April. The $200 \mathrm{~m}$ and $50 \mathrm{~m}$ nests are started at $18 \mathrm{Z}$ and spun up by integrating for $2 \mathrm{~h}$. The subsequent 90-min period 20:0021:29 UTC 8 April is used in the analysis.

Radiation, surface layer, land surface, and planetary boundary layer options used in the model runs are described in Table 1. Ice is initiated by deposition nucleation, contact freezing, and immersion freezing (see Morrison and Pinto (2005) for details on parameterizations used in the model). Homogeneous freezing of cloud droplets is negligible for temperatures observed during ISDAC. The concentration of ice nuclei (IN) acting in deposition and condensation freezing modes is specified from observations using the continuous flow diffusion chamber from the MPACE campaign (Prenni et al., 2007), with a mean of $0.16 \mathrm{~L}^{-1}$. Further discussion of the treatment of IN in deposition freezing mode is included in Sect. 5.2. Cloud droplets are activated in regions of low cloud water content using resolved and subgrid vertical motion (Morrison and Pinto, 2005) and a log-normal aerosol size distribution to derive cloud condensation nuclei spectra following Abdul-Razzak and Ghan (2000). The lognormal dry aerosol size distribution was fit to in-situ measurement from the National Research Council of Canada Convair-580 (personal communication, Peter Liu, Environment Canada, 2010) with a size distribution given by

$$
\frac{d N}{d \ln r}=\frac{N_{\mathrm{t}}}{\sqrt{2 \pi} \ln \sigma} \exp \left\{\frac{\ln ^{2}\left(r / r_{\mathrm{m}}\right)}{2 \ln ^{2} \sigma}\right\}
$$

where $N$ is the number concentration of aerosols and $r$ is the particle radius. The parameters $N_{\mathrm{t}}, r_{\mathrm{m}}$, and $\sigma$ are total number concentration, geometric mean radius and standard deviation of each particle mode, and are given the values
$165 \mathrm{~cm}^{-3}, 1.3 \mu \mathrm{m}$, and 1.4 , respectively. Aerosol composition is assumed to be $30 \%$ insoluble by volume, with the remaining soluble component consisting of ammonium bisulphate.

The microphysical cloud scheme used in this study includes two-moments for cloud droplets, rain, ice, snow, and graupel. This means a prognostic equation for mixing ratio and number concentration is integrated for each of the 5hydrometeor classes. Morrison et al. (2009) provide details of the parameterizations used in this microphysical scheme.

\subsection{Experiment design}

A significant amount of open water was observed during ISDAC along the eastern Alaskan coast. However, this modeling study is focused on the maintenance of decoupled stratocumulus. We therefore removed all regions of open water and set the ocean surface uniformly to sea ice. However, removing the open water had a negligible impact on the simulations presented in this study.

In this model study, WRF is run with high enough resolution to resolve turbulent eddies that contain the most kinetic energy and transport the most heat and momentum, i.e. as a large eddy simulation (LES). However, different from traditional LESs, this study does not use periodic boundary conditions, where an eddy that is advected out one side of the domain enters through the other side of the domain. Rather, eddies from the $200 \mathrm{~m}$ nest are advected into the $50 \mathrm{~m}$ nest and variability with scales finer than $200 \mathrm{~m}$ evolve within the $50 \mathrm{~m}$ nest. This modeling strategy has been successfully applied to simulations of boundary layer clouds in heterogeneous conditions that are directly linked to synoptic systems (for example, see Zhu et al., 2010). In the $50 \mathrm{~m}$ nest, it takes approximately $1 \mathrm{~km}$ for the turbulent structures to spin up (results not shown). 
Table 2. Constants used in this study.

$\begin{array}{ll}c_{p} & \text { Specific heat at constant pressure }=1.0035 \times 10^{3} \mathrm{~J}(\mathrm{~kg} \mathrm{~K})^{-1} \\ g & \text { Gravitational acceleration }=9.81 \mathrm{~m} \mathrm{~s}^{-1} \\ L & \text { Latent heat of condensation }=2.555 \times 10^{6} \mathrm{~J} \mathrm{~kg}^{-1} \\ L_{s} & \text { Latent heat of freezing }=2.898 \times 10^{6} \mathrm{~J} \mathrm{~kg}^{-1} \\ P_{0} & \text { Standard reference pressure }=1000 \mathrm{hPa} \\ R & \text { Specific gas constant }=287 \mathrm{~J} \mathrm{~kg}^{-1} \mathrm{~K}^{-1}\end{array}$

In this study we analyze the budgets of quasi-conserved moist variables, such as $\theta_{\mathrm{e}}$ and total water $\left(q_{\mathrm{t}}\right)$, as well as potential temperature $(\theta)$ and turbulent kinetic energy (TKE) to understand the processes involved in the maintenance and persistence of observed springtime Arctic mixed phase stratocumulus (constants used in this study are provided in Table 2).

The quasi-conserved variables used in our study are $\theta_{\mathrm{e}}$ and $q_{\mathrm{t}}$, where $\theta_{\mathrm{e}}$ is equal to

$\theta_{\mathrm{e}}=\left(T+\frac{L}{c_{p}} q_{\mathrm{v}}\right)\left(\frac{p_{0}}{p}\right)^{\frac{R}{c_{p}}}=\theta+\left(\frac{L}{c_{p}} q_{\mathrm{v}}\right)\left(\frac{p_{0}}{p}\right)^{\frac{R}{c_{p}}}$

and the prognostic equations for $\theta$ and water constituents are

$$
\begin{aligned}
& \frac{\partial \theta}{\partial t}=\left(\frac{p_{0}}{p}\right)^{\frac{R}{c_{p}}} Q_{1}-\boldsymbol{u} \cdot \nabla \theta-w \frac{\partial \theta}{\partial z} \\
& \frac{\partial q_{*}}{\partial t}=Q_{2 *}-\boldsymbol{u} \cdot \nabla q_{*}-w \frac{\partial q_{*}}{\partial z}
\end{aligned}
$$

where $Q_{1}$ is diabatic heating, composed of radiative heating $\left(Q_{\mathrm{r}}\right)$ and condensational heating $\left(Q_{\mathrm{c}}\right)$, and $Q_{2 *}$ is diabatic moistening due to phase changes. Sedimentation, or gravitational settling, is included in the $Q_{2 *}$ term. In Eq. (4), $q_{*}$ can be vapor $\left(q_{\mathrm{v}}\right)$, liquid $\left(q_{\mathrm{c}}\right)$, ice + snow + qraupel $\left(q_{\mathrm{i}}\right)$, or total water $\left(q_{\mathrm{t}}=q_{\mathrm{v}}+q_{\mathrm{c}}+q_{\mathrm{i}}\right)$.

To separate mesoscale and turbulent variability, all turbulent fluxes are calculated with 15 min averaged fields. Fifteen minutes is approximately the time scale between mesoscale variability and the "energy-containing" scales in the retrieved vertical velocity spectra (results not shown). For example, for vertical fluxes, the turbulent vertical flux is, $\overline{w^{\prime} q_{*}^{\prime}}=$ $\overline{w q_{*}}-\bar{w} \overline{q_{*}}$, where primes denote deviations from the temporal averages and overbars signify temporal averages over $15 \mathrm{~min}$ (equal to the average over 1800 time steps). Vertical profiles are calculated by horizontally averaging (denoted with angled brackets) across a $6.5 \mathrm{~km} \times 6.5 \mathrm{~km}$ square domain, $1 \mathrm{~km}$ away from horizontal boundaries. The budgets expressed in Eqs. (3-4) are also averaged over updrafts and downdrafts separately to investigate the turbulent dynamics that maintain the mixed layer and cloud layer structures.

In a nearly horizontally homogenous system (where the length scale of the most energetic turbulent eddies is much smaller than the characteristic scale of the eddy correlations) the TKE-budget can be written as (see Garratt, 1992, pg. 33, eqn 2.74a):

$$
\underbrace{\frac{\partial \bar{e}}{\partial t}}_{\mathrm{E}}=\underbrace{\frac{g}{\theta_{0}} \overline{w^{\prime} \theta_{\mathrm{v}}^{\prime}}}_{\mathrm{B}}-\underbrace{-\left(\overline{u^{\prime} w^{\prime}} \frac{\partial \bar{u}}{\partial z}+\overline{\left.v^{\prime} w^{\prime} \frac{\partial \bar{v}}{\partial z}\right)}\right.}_{\mathrm{S}} \underbrace{-\frac{\partial \overline{w^{\prime} e}}{\partial z}}_{\mathrm{T}} \underbrace{-\frac{\partial \overline{w^{\prime} p^{\prime}}}{\bar{\rho} \partial z}}_{\mathrm{P}} \underbrace{-\varepsilon}_{\mathrm{D}},
$$

where $e=0.5\left(u^{\prime} u^{\prime}+v^{\prime} v^{\prime}+w^{\prime} w^{\prime}\right)$,

$\theta_{\mathrm{v}}=\theta\left(1+0.61 q_{\mathrm{v}}-q_{\mathrm{i}}-q_{\mathrm{c}}\right)$,

and buoyancy flux $=\overline{w^{\prime} \theta_{\mathrm{v}}^{\prime}}$

The term $\mathrm{E}$ is storage, $\mathrm{B}$ is buoyancy production, $\mathrm{S}$ is shear production, $\mathrm{T}$ is turbulent vertical transport, $\mathrm{P}$ is pressure transport, and D is viscous dissipation.

\section{Validation of $1 \mathrm{~km}$ nest at Barrow}

The model simulates the vertical extent and ice water content (IWC) of the predominantly ice cloud that was observed between 0-8 Z (results not shown). The model also simulates the mixed phase stratocumulus that was observed starting at $8 \mathrm{Z}$, with maximum liquid water content (LWC) at $1.3 \mathrm{~km}$, and the slow descent of the cloud from $8 \mathrm{Z} 8$ April to $12 \mathrm{Z}$ 9 April (compare Fig. 3a, b, c, d). At times, multiple layers of liquid are produced within the model, consistent with ground-based observations. Modeled IWC in the AMPS is underestimated by a factor of 3-4, a difference that is somewhat larger than the expected uncertainty in retrieved IWC. However, qualitatively, the model does tend to show a relative increase in IWC in a layer near the surface, which is consistent with the radar-derived IWC profiles. The $1 \mathrm{~km}, 200 \mathrm{~m}$, and $50 \mathrm{~m}$ nests produce AMPS with equivalent structure and magnitude (figure not shown). Cold temperatures aloft (estimated from the soundings) descend more slowly in the simulation causing a single-layer AMPS to form at $1.2 \mathrm{~km}$ from 18-22 Z, while observations show cloud tops closer to $800 \mathrm{~m}$ at this time. However, this difference in inversion base height between the model and sounding does not change the qualitative, mean state characteristics, i.e. both have cloud layers that are decoupled from the surface layer.

In Fig. 5 we compare $w$, LWP, and IWP power spectra at Barrow for the 2-h period 20-22 Z from retrievals, the $1 \mathrm{~km}$ nest and $50 \mathrm{~m}$ nest $(50 \mathrm{~m}$ nest values are taken to the west of Barrow at $71.33^{\circ} \mathrm{N}, 156.91^{\circ} \mathrm{W}$; red star in Fig. 6). The $w$ time series used in this analysis are vertical averages over the layer containing cloud liquid water, as vertical velocity structures were typically vertically coherent in nature. Looking at the $w$ spectra first, the $50 \mathrm{~m}$ nest is reproducing the variability well into the inertial subrange $\left(v>\sim 0.01 \mathrm{~s}^{-1}\right)$, while the $1 \mathrm{~km}$ nest can only resolve time scales longer than $\sim 10$ min $\left(v<\sim 2 \times 10^{-3} \mathrm{~s}^{-1}\right)$, which is consistent with the $7 \mathrm{~m} \mathrm{~s}^{-1}$ horizontal wind speed and a $4 \Delta x$ resolution. It is interesting to note that the $1 \mathrm{~km}$ nest can simulate similar coarse-scale variability and structure as the $50 \mathrm{~m}$ nest despite not resolving small scales. Similar results are seen for the 

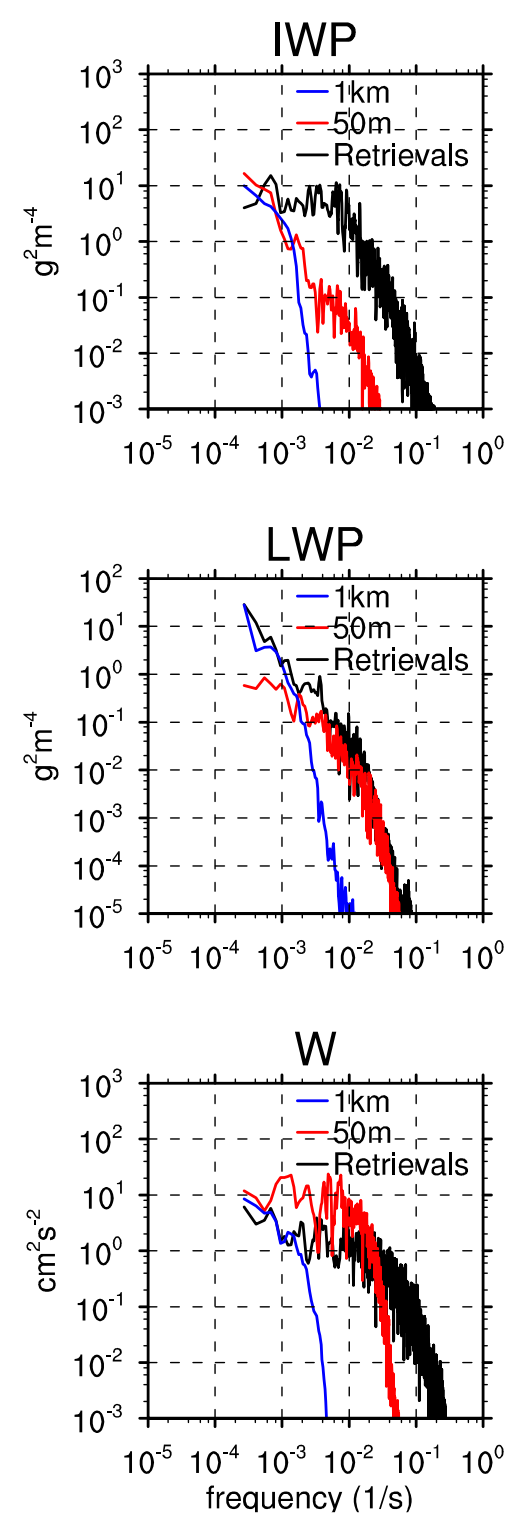

Fig. 5. IWP (top), LWP (middle), and $w$ (bottom) spectra at Barrow for the $2 \mathrm{~h}$ period 20-22 Z 8 April 2008 from retrievals (black), $1 \mathrm{~km}$ nest (blue) and $50 \mathrm{~m}$ nest (red), in units of $\mathrm{g}^{2} \mathrm{~m}^{-4}, \mathrm{~g}^{2} \mathrm{~m}^{-4}$, and $\mathrm{cm}^{2} \mathrm{~s}^{-2}$, respectively. The spectra for the $50 \mathrm{~m}$ nest are obtained 0.30 degrees $(\sim 7 \mathrm{~km})$ west of Barrow, marked by the red star in Fig. 6.

LWP; both the $50 \mathrm{~m}$ and $1 \mathrm{~km}$ nests have similar variability on $10-20 \mathrm{~min}$ time scales while only the $50 \mathrm{~m}$ resolves the finer scale variability. IWP spectra show that the $50 \mathrm{~m}$ nest is underestimating variability on small scales, even though these scales are better simulated in the LWP and $w$ spectra, suggesting difficulties with initiation and/or growth of cloud ice and snow in the model.

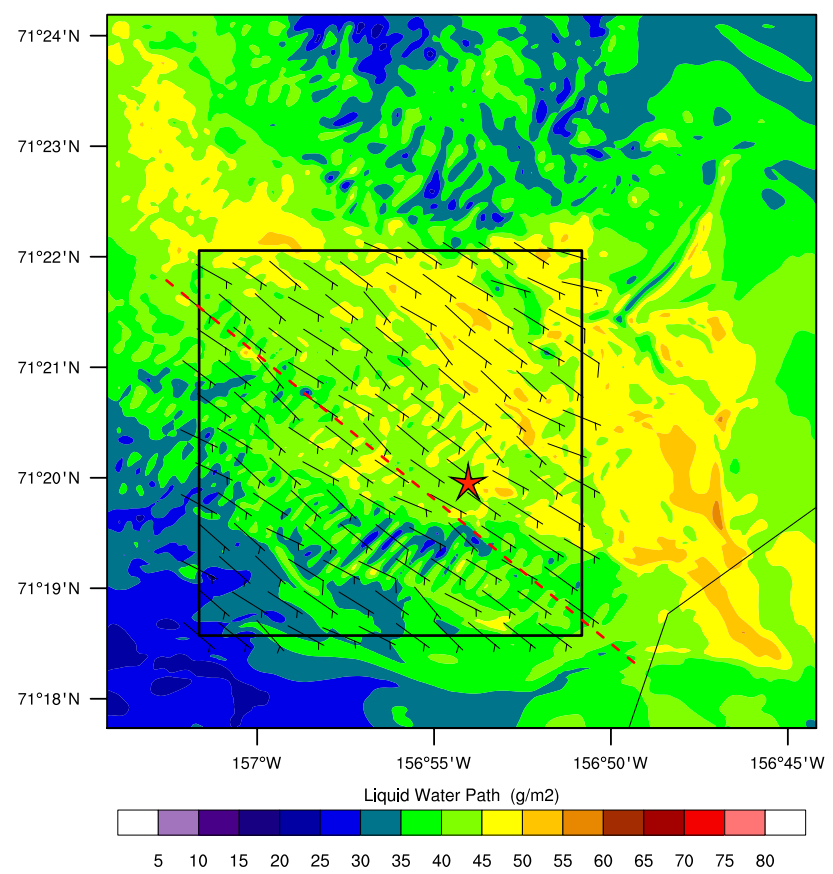

Fig. 6. Liquid water path (color) and winds (flags) at maximum liquid water level at $20 \mathrm{Z}$ on 8 April 2008 for the $50 \mathrm{~m}$ nest. A half barb on the wind flags indicates $5 \mathrm{~m} \mathrm{~s}^{-1}$ and a full barb $10 \mathrm{~m} \mathrm{~s}^{-1}$. The square marks the region used to make total, downdraft, and updraft averages $(130 \times 130$ grid points $)$. The red star marks the location of vertical profiles plotted in Fig. 2 and the $50 \mathrm{~m}$ spectra in Fig. 5. The red dashed line marks the diagonal slice plotted in Fig. 7. Barrow, Alaska is located directly to the east of the red star, to the right of thin black lines in the lower right marking the Alaska coastline.

\section{Nested LES simulations}

\subsection{Comparison with a sounding at Barrow}

In this study we focus our analysis on the single layer AMPS that persisted from $18-22 \mathrm{Z}$ in the model. In Fig. 2, we compare the environmental conditions to the west of Barrow at $20 \mathrm{Z}$ in the $50 \mathrm{~m}$ nest (hereafter referred to as the LES) to the nearest-in-time sounding taken at Barrow at 17:34 Z. Note that these vertical profiles are for different times at different locations since the modeled cloud structure evolves slightly later than observed, and this study focuses on the region to the west of Barrow with uniform surface conditions. The red star in Fig. 6 shows the location of vertical profiles plotted in Fig. 2b. The LES simulates a well-mixed surface layer up to $\sim 400 \mathrm{~m}$ and a second mixed layer associated with the cloud (referred to hereafter as the cloudy mixed layer or simply mixed layer) as in the sounding; however, the intervening stable layer is somewhat deeper and offset vertically in the LES relative to the observations. The simulated cloud-top temperature inversion strength of $5 \mathrm{~K}$ is slightly greater than the observed $4 \mathrm{~K}$ inversion; however, the 
simulated humidity inversion of $0.4 \mathrm{~g} \mathrm{~kg}^{-1}$ is slightly weaker than observed. Cloud water extends into the temperature inversion by approximately $50 \mathrm{~m}$ in both the LES and sounding. On average, the cloud water maximum is at the humidity inversion base and $23 \%$ of simulated cloud liquid water is located within the inversion. Unfortunately, this vertical structure cannot be validated since the remote-sensor observations do not contain sufficient information on the vertical distribution of liquid water in mixed-phase clouds. Observed winds indicate shear in the surface layer and weaker winds within the cloudy mixed layer. While qualitatively similar in many regards, the LES shows larger shear at cloud top; part of this difference may be due to vertical smoothing of the radiosonde measurements during data acquisition.

\subsection{Comparison with aircraft measurements}

A research flight was conducted on 8 April with the National Research Council of Canada Convair-580 (McFarquhar et al., 2011). Between 22:27 and 23:00 UTC a series of ramped ascents and descents through the cloud layer were executed between Barrow and $71.8^{\circ} \mathrm{N}, 160^{\circ} \mathrm{W}$. Comparisons are made for this space and time between measured (see Avramov et al., 2011, Fig. 10) and modeled (see Supplement Fig. 1) vertical profiles of horizontally averaged droplet number concentrations (NC), LWC, ice number concentration (NI) for sizes larger than 100 microns, and IWC. The modeled NC is essentially determined by the aerosol concentration specified in the model and is within the range of observed values. Modeled LWC is at the high end of the observational estimate and mean values are $50 \%$ larger than measured mean values. Modeled NI is $\sim 0.751$ from the base of the cloud to $0.5 \mathrm{~km}$, which is larger than the observational estimate but within a factor of two of the mean. Our mean peak IWC values of $\sim 0.018 \mathrm{~g} \mathrm{~m}^{-3}$ above $500 \mathrm{~m}$ are lower than the baseline IWC observational estimates; however, as discussed by Avramov et al. (2011), IWC calculations from measured size distributions can vary by at least a factor of five when ice crystal habit assumptions are taken into account. With this significant observational uncertainty, the degree to which the model underestimates IWC, if at all, cannot be determined. In general, considering the observational uncertainties and the difficulty in comparing data sets with differing spatial and temporal sampling, these comparisons indicate that the LES results are not inconsistent with in situ measurements.

These comparisons with aircraft observations provide further insight into the modeled ice nucleation processes. Depositional freezing is parameterized to only be active if NI drops below a fixed threshold value (Morrison et al., 2009). In our primary simulation, NI generally exceeded the specified threshold of $0.161^{-1}$, meaning that contact and immersion freezing dominated the modeled ice nucleation. In sensitivity simulations, deposition freezing only became significant when the threshold was greater than $\sim 0.71^{-1}$, or the approximate average modeled NI. Simulations with much higher thresholds lead to glaciation of the cloud. Since the aircraft observed NI was actually slightly smaller than $0.71^{-1}$, depositional thresholds higher than this value are not justified. Therefore, the IN concentrations of about $81^{-1}$ measured during the 8 April flight (McFarquhar et al., 2011) must be representative of concentrations in the free troposphere but not those accessible to the cloud layer itself. The relative consistency between modeled and observed NI supports a low threshold value for the deposition freezing parameterization. Small concentrations of IN within the cloud layer relative to those measured above cloud top may be explained by a large sink of IN through precipitation versus a much smaller source through entrainment at cloud top (Fridlind et al., 2011).

\subsection{Vertical structure along mean wind in cloud layer}

The spatial distribution of LWP in the LES at $20 \mathrm{Z}$ is plotted in Fig. 6. The square in the figure marks a region that is $1.0 \mathrm{~km}$ away from any boundary and consistently has single layer AMPS with cloud tops at $\sim 1.29 \mathrm{~km}$ for the $20-22 \mathrm{Z}$ period. This region is used for statistics discussed in the following sections. Figure 7 shows the vertical structure of various fields along the red dashed line in Fig. 6, which is approximately parallel to mean winds in the cloud layer. This figure depicts a single layer cloud with top at $\sim 1.29 \mathrm{~km}$, base at $\sim 1 \mathrm{~km}$, and cloud water extending into the inversion by about $50 \mathrm{~m}$. The inversion base is at $1250 \mathrm{~m}$. Cloud ice forms within the liquid cloud layer (Fig. 7b), sometimes very near the top, and precipitates below the cloud layer. The precipitating ice sublimates to some degree in a dry layer below the cloud, but tends to grow again in the relatively moist nearsurface layer.

Characteristic subgrid vertical velocity is estimated from predicted subgrid turbulent kinetic energy, assuming isentropic turbulence, as $w_{\mathrm{sg}}^{\prime}=\left(\frac{2}{3} \mathrm{TKE}\right)^{\frac{1}{2}}$. Subgrid vertical velocity is seen in three physically distinct regions: at the inversion top, in a layer encompassing the cloudy mixed layer, and near the surface (Fig. 7c). The magnitude of the subgrid vertical velocity in the mixed layer is $\sim 4 \mathrm{X}$ smaller than the resolved vertical velocity but still significant. Resolved downdrafts are stronger and narrower than updrafts (Fig. 7d), consistent with generation by cloud-top cooling. The strongest vertical motions are generally confined to the cloud layer itself. Small-scale variability is seen within and above the inversion. Generally weak vertical motions also occur below $0.7 \mathrm{~km}$.

Figure $7 \mathrm{e}, \mathrm{f}$ show $\theta_{\mathrm{e}}$ and total water $\left(q_{\mathrm{t}}\right)$ along the diagonal slice. Since these two fields are quasi-conserved during adiabatic changes including vapor-liquid phase changes $\left(\theta_{\mathrm{e}}\right.$ is not conserved during liquid-ice phase changes), they are commonly used to identify mixed-layer structure and define idealized mixed-layer models. A mixed layer is seen in Fig. $7 \mathrm{e}, \mathrm{f}$ to extend from the base of the inversion at $1250 \mathrm{~m}$ 

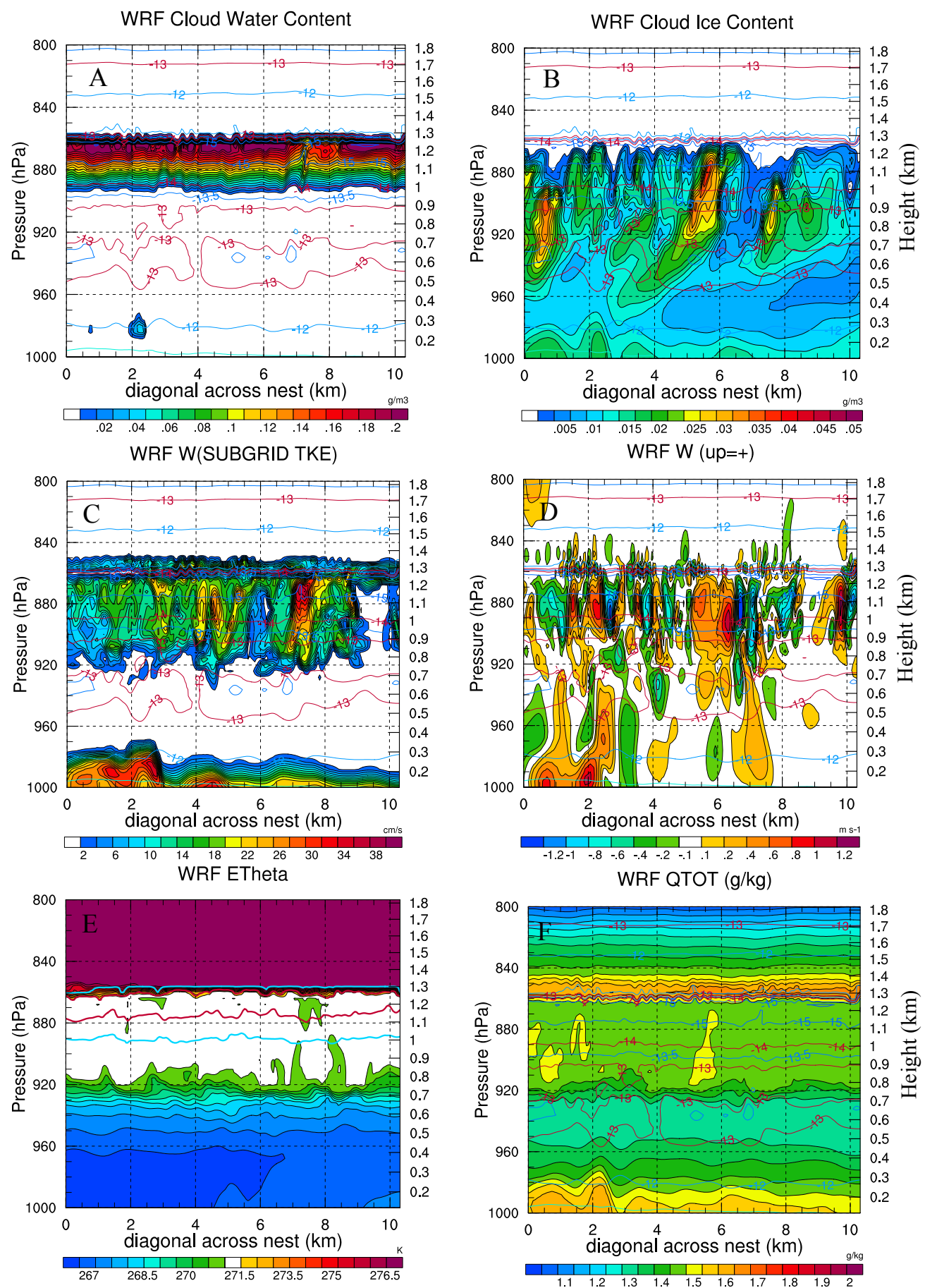

Fig. 7. Vertical structure at $20 \mathrm{Z}$ along mean cloud layer wind from $50 \mathrm{~m}$ nest. (A) Cloud water, in units of $\mathrm{g} \mathrm{kg}^{-1}$. (B) Cloud ice, in units of $\mathrm{g} \mathrm{kg}^{-1}$. (C) Subgrid $w$, in units of $\mathrm{cm} \mathrm{s}^{-1}$. (D) Vertical velocity, in units of $\mathrm{m} \mathrm{s}^{-1}$. (E) Equivalent potential temperature, in units of K. Red (blue) lines are contours of $q_{\mathrm{c}}=0.12(0.01) \mathrm{g} \mathrm{m}^{-3}$ to identify $\max (\mathrm{min})$ of the cloud layer. (F) Total water, in units of $\mathrm{g} \mathrm{kg}^{-1}$. Isotherms are shown with colored contour lines in all figures except $(\mathbf{E})$.

(just below cloud top) to $800 \mathrm{~m}, 200 \mathrm{~m}$ below cloud base. Total water maxima are seen at and above the inversion and at the surface, with a region of drier air below the mixed layer. Small-scale fluctuations penetrating the interfaces at the top and bottom of the mixed layer are clearly seen in Fig. 7e, f. The role of these fluctuations in maintaining the mixed layer is described in the next section. 


\subsection{Total domain averages}

\subsubsection{Buoyancy fluxes}

Figure 8 shows the vertical buoyancy flux, $\overline{w^{\prime} \theta_{\mathrm{v}}^{\prime}}$, and $\theta_{\mathrm{e}}$ averaged temporally over $90 \mathrm{~min}$ and horizontally over the square domain in Fig. 6. Positive buoyancy flux occurs in the mixed layer from about 0.9 to $1.24 \mathrm{~km}$ and near the surface below $0.2 \mathrm{~km}$. Weak negative buoyancy flux is present between these two layers. The cloud top is capped by a layer of negative buoyancy flux, associated with the damping effect of entraining air from the temperature inversion. This entrainment is forced by radiative cooling. The peak negative flux occurs at $1.27 \mathrm{~km}$ (Fig. 8b), $30 \mathrm{~m}$ above the top of the mixed layer. Motions in regions with positive buoyancy flux are stabilizing, producing TKE at the expense of potential energy. Motions in regions with negative buoyancy flux are destabilizing, reducing TKE to produce potential energy. Note that the cloud top actually resides in a region of negative buoyancy flux. The small difference between the buoyancy flux and potential temperature flux $\left(\overline{w^{\prime} \theta^{\prime}}\right.$, red curves) indicates that water variations are making a negligible contribution to the buoyancy flux.

Figure $8 \mathrm{~b}, \mathrm{c}$ are the same curves as in Fig. 8a enlarged to show the correspondence between buoyancy flux and a $\theta_{\mathrm{e}}-$ based layer definition for the upper entrainment zone (8b) and the lower entrainment zone (8c). The dash-dot gray lines indicate the $\theta_{\mathrm{e}}$ slopes in the mixed layer and the $\sim$ dry adiabatic lapse rate above (below) the upper (lower) entrainment zones. The depth of the entrainment zones is estimated as the region where the slope of $\theta_{\mathrm{e}}$ deviates from the constant slopes marked with the gray dash-dot lines; specifically, $1.24-1.3 \mathrm{~km}($ depth $=60 \mathrm{~m})$ for the entrainment zone at cloud top and $0.62-0.82 \mathrm{~km}$ (depth $=200 \mathrm{~m}$ ) for the entrainment zone at the base of the mixed layer. Therefore, the $\theta_{\mathrm{e}}$ profile indicates that there are effectively two mixed-layers, one being the actual boundary layer from the surface up to about $400 \mathrm{~m}$ and the other being the cloud-driven mixedlayer. Thus, the cloud is decoupled from the surface and does not derive much (or any) of its energy from surface forcing.

\subsubsection{Potential temperature tendencies}

Longwave radiative cooling dominates over condensation and advection warming tendencies within the upper entrainment zone, causing the net potential temperature tendency in this zone to be a cooling of up to $-40 \mathrm{~K} \mathrm{day}^{-1}$ (Fig. 9a). The maximum cooling tendency is located somewhat higher in the entrainment zone than the longwave cooling peak due to the turbulent vertical divergence of $\theta_{\mathrm{e}}$ fluxes (a cooling) between 1.27-1.35 km (WTP in Fig. 9). The total advective tendency is also significant within the upper entrainment zone, where values of $+20-40 \mathrm{~K} \mathrm{day}^{-1}$ occur (ADV in Fig. 9). Contributions from both horizontal and vertical flow exceed $30 \mathrm{~K} \mathrm{day}^{-1}$ (results not shown), but tend to par-
$\mathrm{K}$
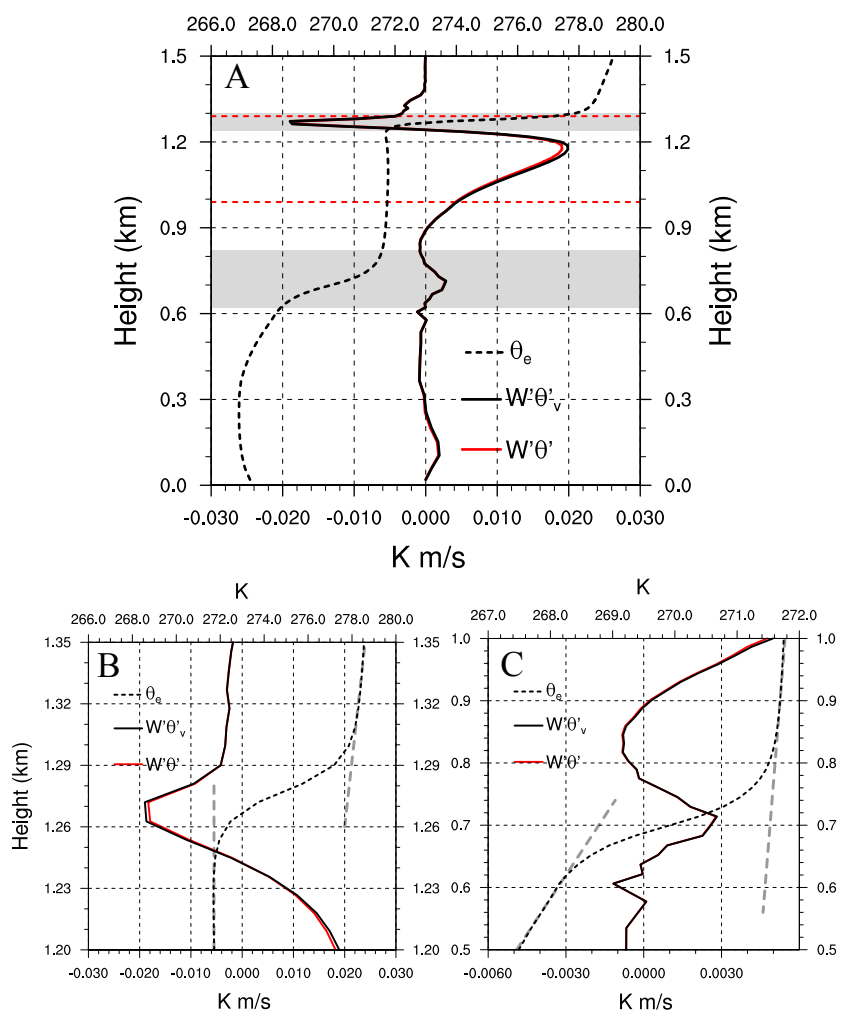

Fig. 8. Buoyancy fluxes averaged over the square box, where black(red) lines show $\overline{w^{\prime} \theta_{\mathrm{v}}^{\prime}}\left(\overline{w^{\prime} \theta^{\prime}}\right)$ and equivalent potential temperature $\left(<\theta_{\mathrm{e}}>\right)$ is shown with a dashed line, in units of $\mathrm{K} \mathrm{m} \mathrm{s}^{-1}$ and $\mathrm{K}$, respectively. Cloud layer top and base indicated by red dashed lines. (A) Surface to $1.5 \mathrm{~km}$. Entrainment zones indicated with gray shading. (B) Cloud top entrainment zone. (C) Below mixed layer entrainment zone. Long dashed gray lines show constant $\theta_{\mathrm{e}}$ slopes used to estimate the depth of the entrainment zones: 1.24 $1.3 \mathrm{~km}=60 \mathrm{~m}$ at cloud top and $0.62-0.82 \mathrm{~km}=200 \mathrm{~m}$ below mixed layer.

tially cancel such that the total advective tendency is smaller. The total advective term is highly variable in time, with the standard deviation of 15-min horizontally- and verticallyaveraged advective tendencies being $26.6 \mathrm{~K} \mathrm{day}^{-1}$ compared to only $2.9 \mathrm{~K} \mathrm{day}^{-1}$ for longwave cooling. This variability is primarily due to advection by mean fields, as the ratio of standard deviations for vertical mean and eddy advective tendencies is $16 / 5$. Contributions to $\theta_{\mathrm{e}}$ tendencies from solar radiation are negligible.

Longwave cooling effects extend $80 \mathrm{~m}$ down into the mixed-layer (130 $\mathrm{m}$ into the cloud), with average values near $-80 \mathrm{~K} \mathrm{day}^{-1}$ at the mixed-layer top (Fig. 9a). However, the effects of this cooling are largely offset by turbulent vertical convergence of $\theta_{\mathrm{e}}$ flux (a warming) between $1.18-1.27 \mathrm{~km}$, which is due to entrainment of sensible heat from above the temperature inversion. In this case, the surface is warmer than the cloud, causing a net longwave warming at cloud 


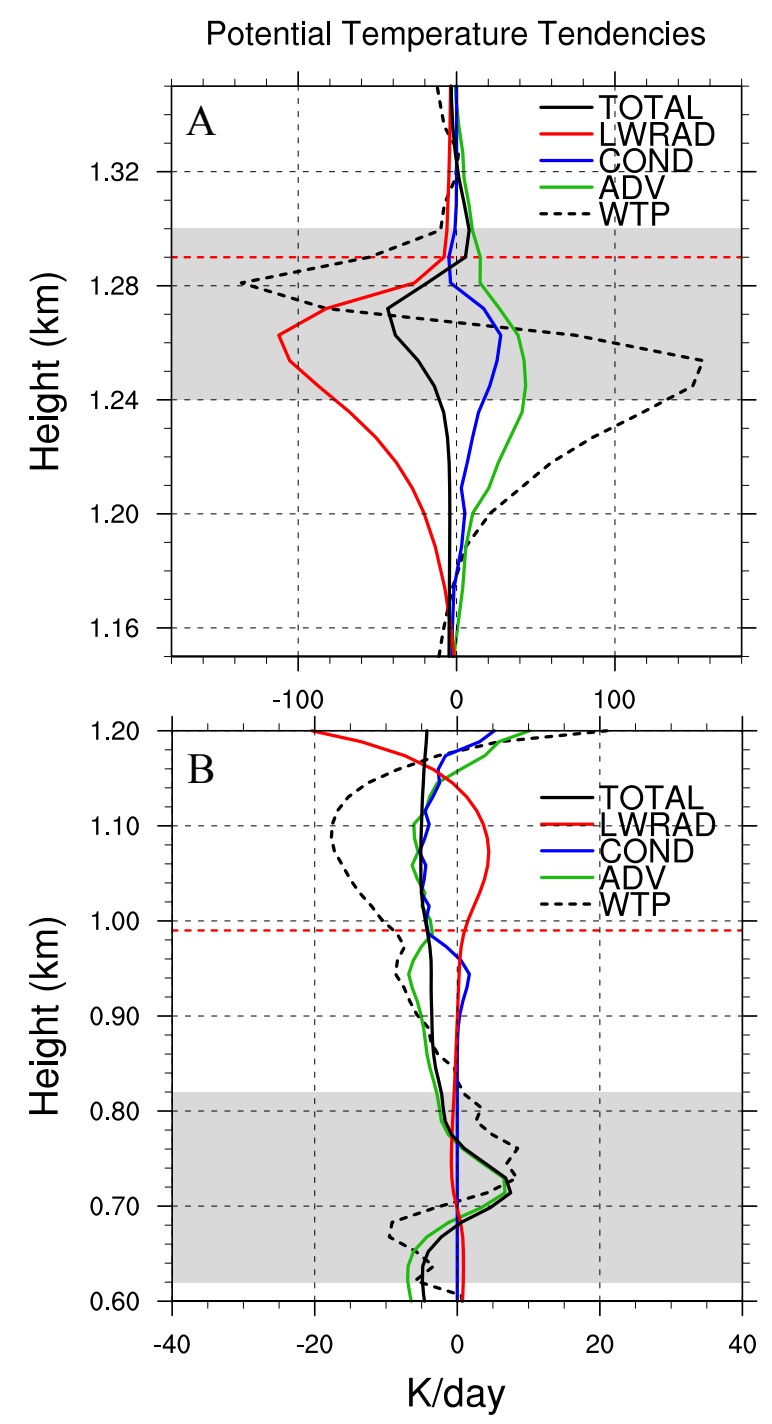

Fig. 9. Potential temperature tendencies averaged over the square box, in units of $\mathrm{Kday}^{-1}$. (A) The upper region of the mixed layer and cloud top entrainment zone. (B) Mixed layer and lower entrainment zone. Tendencies plotted are total tendency (TOTAL, black), condensation/evaporation (COND, blue), longwave radiation (LWRAD, red), total advection (ADV, green), and vertical eddy advection (WTP, black dash). Tendencies are horizontally averaged across the square domain and then temporally averaged over the 20:00 Z-21:29 Z period. Note change in scale between (A) and (B). Entrainment zones indicated with gray shading. Cloud layer top and base indicated by red dashed lines.

base (0.97-1.14 km) (Fig. 9b). This warming is largely balanced by cooling from evaporation and $\theta_{\mathrm{e}}$ flux divergence. The general compensation of terms within the mixed-layer leads to a relatively uniform total $\theta_{\mathrm{e}}$ tendency profile at about $-4 \mathrm{Kday}^{-1}$.

\subsubsection{Turbulent kinetic energy tendencies}

TKE tendency terms are calculated following Eq. (5) and then averaged horizontally across the total square domain. The shear (S), buoyancy (B), TKE transport (T), and residual $(\mathrm{R}=\mathrm{P}+\mathrm{D})$ terms are plotted in Fig. 10. The storage term is negligible so $\mathrm{B}+\mathrm{S}+\mathrm{T}+\mathrm{R} \approx 0$. The gray shading in Fig. 10 marks the entrainment zones. The mean resolved TKE is approximately constant $0.4-0.5 \mathrm{~m}^{2} \mathrm{~s}^{-2}$ within the mixed layer, decreasing to below $0.1 \mathrm{~m}^{2} \mathrm{~s}^{-2}$ above $1.32 \mathrm{~km}$ and below $0.7 \mathrm{~km}$.

In the upper entrainment zone, negative TKE tendencies due to buoyancy effects associated with the temperature inversion, are largely balanced by TKE generation by pressure transport, as the dissipation contribution to $\mathrm{R}$ can only be negative. At the base of this entrainment zone, TKE is primarily produced by shear and is transported downward into the mixed layer. Within the mixed layer, TKE is produced by buoyancy effects resulting from radiative cooling above $1.15 \mathrm{~km}$ and evaporative cooling plus advection below $1.15 \mathrm{~km}$ (see Fig. 9). This buoyancy, combined with shear, produces TKE within the mixed layer, much of which is also dissipated within the mixed layer. Buoyancy contributes to negative TKE tendencies near the mixed-layer bottom; however, this term is small relative to TKE transport from mixed-layer top to bottom. All TKE tendencies approach zero just below the mixed-layer bottom, consistent with this layer being energetically decoupled from the lower troposphere and surface .

\subsubsection{Averaged water tendencies and mean fields}

Vapor, liquid water, and ice tendencies, as well as mean vertical velocity, $\theta_{\mathrm{e}}$, vapor, and cloud water profiles averaged over the square domain in Fig. 6 and temporally averaged over the 90-min period are plotted in Fig. 11. Figure 11a shows the contribution of cloud water, cloud ice, and water vapor to the total water tendency. The entrainment zones are indicated with gray shading. Water vapor decreases throughout the upper entrainment zone, partially due to condensation, resulting in positive cloud water tendencies in this zone. Small positive ice tendencies start just below the top of the upper entrainment zone. The loss of total water in the mixed layer is relatively constant with height, resulting from loss of both cloud liquid water and water vapor above $1 \mathrm{~km}$ and only vapor below $1 \mathrm{~km}$. Below the lower entrainment zone, vapor increases due to sublimating ice precipitation, surface moisture fluxes, and mean horizontal advection.

On average a weak subsidence of $-0.4 \pm 0.4 \mathrm{~cm} \mathrm{~s}^{-1}$ occurs at and above cloud top (Fig. 11b). A mean subsidence of up to $-2.5 \mathrm{~cm} \mathrm{~s}^{-1}$ occurs within the mixed layer, with large variability. Weak upward motion occurs below the mixed layer. At the top of the upper entrainment zone, mean vertical velocity goes to zero with relatively limited variability $\left(< \pm 0.5 \mathrm{~cm} \mathrm{~s}^{-1}\right)$, suggesting little movement through this 


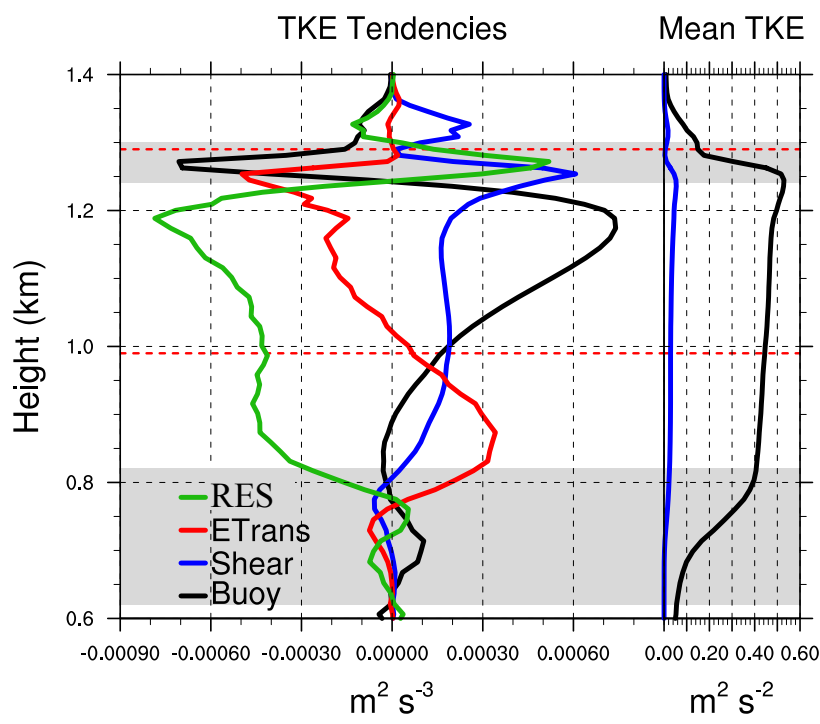

Fig. 10. Horizontally and temporally averaged profiles of turbulent kinetic energy (TKE) and TKE tendencies. (Left) Resolved TKE tendencies in units of $\mathrm{m}^{2} \mathrm{~s}^{-3}$, with terms defined in text. Residual = pressure transport plus dissipation. (Right) Mean resolved (black) and subgrid (blue) TKE, in units of $\mathrm{m}^{2} \mathrm{~s}^{-2}$. Entrainment zones indicated with gray shading. Cloud layer top and base indicated by red dashed lines.

interface. Vertical velocities in individual up- and downdrafts within the mixed layer are often 100 times larger than these mean values. Twenty three percent of the vertically integrated cloud liquid water is located within the inversion (Fig. 11c). Maximum liquid water occurs at the water vapor minimum, which is at the inversion base. Significantly larger values of water vapor occur above and below the cloud layer.

Time series of 15-min averaged water content tendencies in the upper entrainment zone and mixed layer are plotted in Fig. 12. A close compensation between cloud liquid water and water vapor tendencies is seen in the upper entrainment zone, always resulting in a net loss of total water of between -50 to $-200 \mathrm{~g} \mathrm{~m}^{-2} \mathrm{day}^{-1}$. The ice tendency in this zone is negligible. In the mixed layer, the large negative total water tendency $\left(-300-900 \mathrm{~g} \mathrm{~m}^{-2}\right.$ day $\left.^{-1}\right)$ is dominated by a loss of water vapor. Loss of cloud water has much less variability than water vapor, and contributes between -100 to $-500 \mathrm{~g} \mathrm{~m}^{-2}$ day $^{-1}$ during each 15 -min period. Positive ice tendencies counteract some of the general loss. While the height of the mixed-layer top remains steady over the 90min analysis period, the mixed layer base moves downward at a rate of $50 \mathrm{~m} \mathrm{~h}^{-1}$ (results not shown), possibly affecting the evolution of these layer integrals.

Water content tendencies are given by (4), where term $Q_{2 *}$ represents diabatic moistening or microphysical processes (which include both phase transitions and sedimentation and is indicated by "MICROPHY" in the figures), and the last two terms represent horizontal and vertical advective tenden-
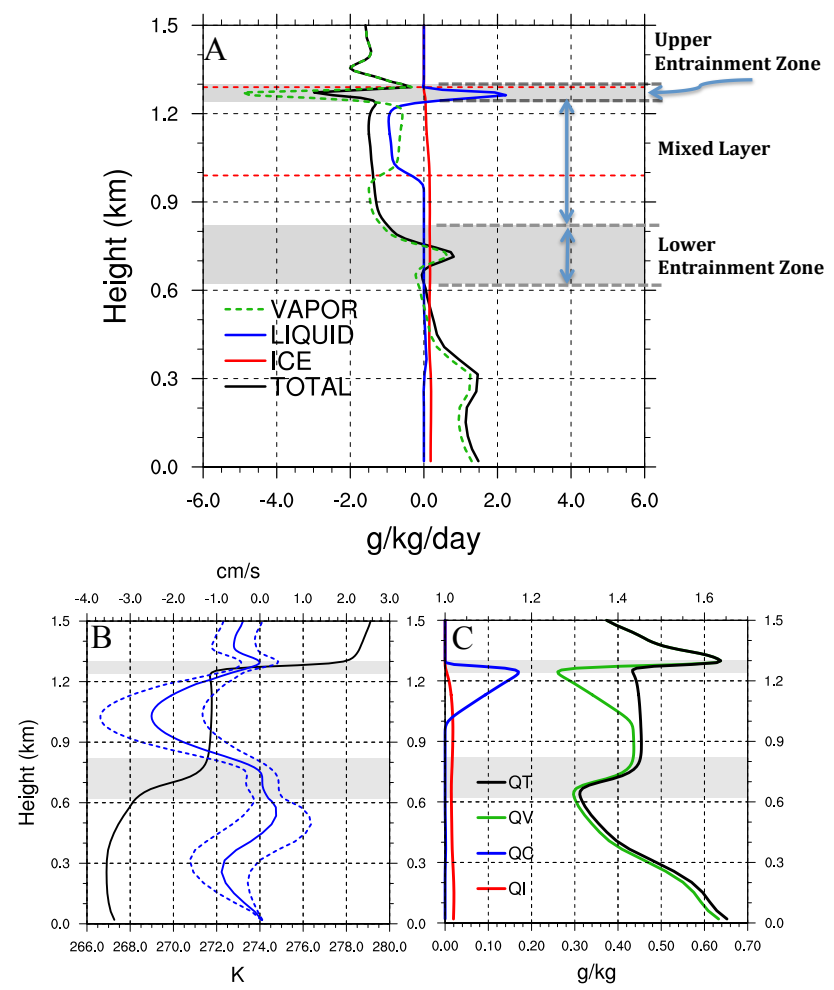

Fig. 11. Tendencies averaged over the square box calculated from 15-min averages. Entrainment zones indicated with gray shading. (A) Cloud water, vapor, ice, and total water tendencies, in units of $\mathrm{g} \mathrm{kg}^{-1}$ day $^{-1}$. Gray dash lines denote boundaries of cloud top entrainment zone, mixed layer, lower entrainment zone. Positive (negative) indicates water gained (lost) by the layer. Cloud layer top and base indicated by red dashed lines. (B) Mean resolved vertical velocity (blue, dash lines are \pm one standard deviation) and equivalent potential temperature in black, in units of $\mathrm{cm} \mathrm{s}^{-1}$ and $\mathrm{K}$, respectively. (C) Mean total water, cloud liquid water, cloud ice water, and water vapor, in units of $\mathrm{g} \mathrm{kg}^{-1}$. Note that the cloud layer is primarily in the mixed layer and extends approximately $50 \mathrm{~m}$ into the upper entrainment zone.

cies, respectively. Since advective tendencies in the model are formulated in flux form, mean flow and eddy contributions to the advective tendency are calculated offline as:

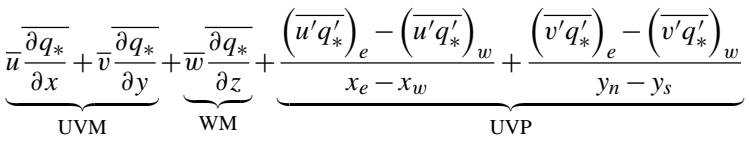

$$
\begin{aligned}
& +\underbrace{\frac{\partial\left(\overline{w^{\prime} q_{*}^{\prime}}\right)}{\partial z}}_{\mathrm{WP}} \approx \underbrace{\mathrm{ADV}}_{\mathrm{ADV}}
\end{aligned}
$$

where ADV is the total advective tendency calculated in the model, $\bar{u}, \bar{v}, \bar{w}, \overline{q_{*}}$ are 15 -min averaged zonal wind, meridional wind, vertical wind, and water constituents, respectively, and $\overline{u^{\prime} q_{*}^{\prime}}, \overline{v^{\prime} q_{*}^{\prime}}, \overline{w^{\prime} q^{\prime}}$ are resolved turbulent fluxes calculated from total flux and mean fields. $x_{e}, x_{w}, y_{n}, y_{s}$ are 


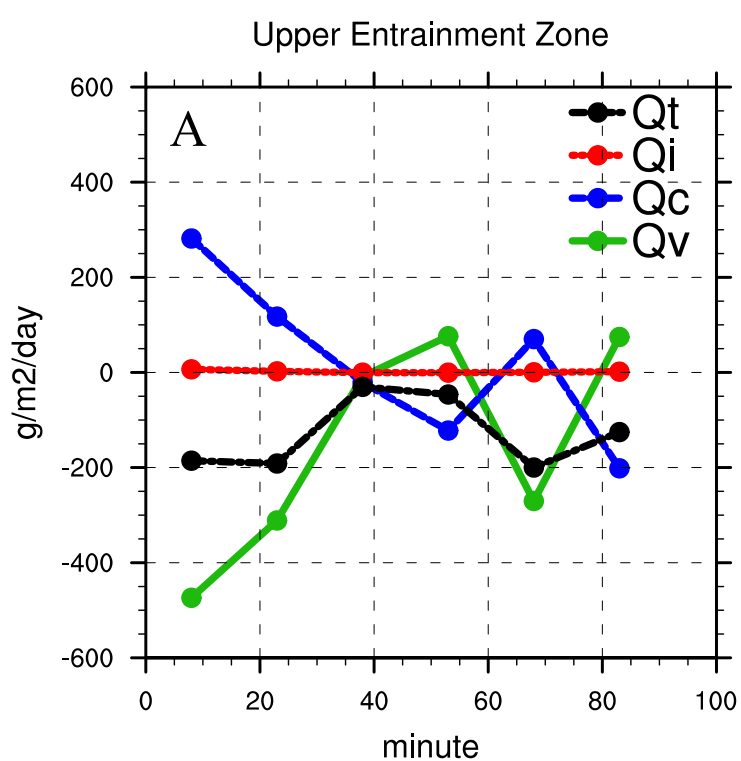

Mixed Layer

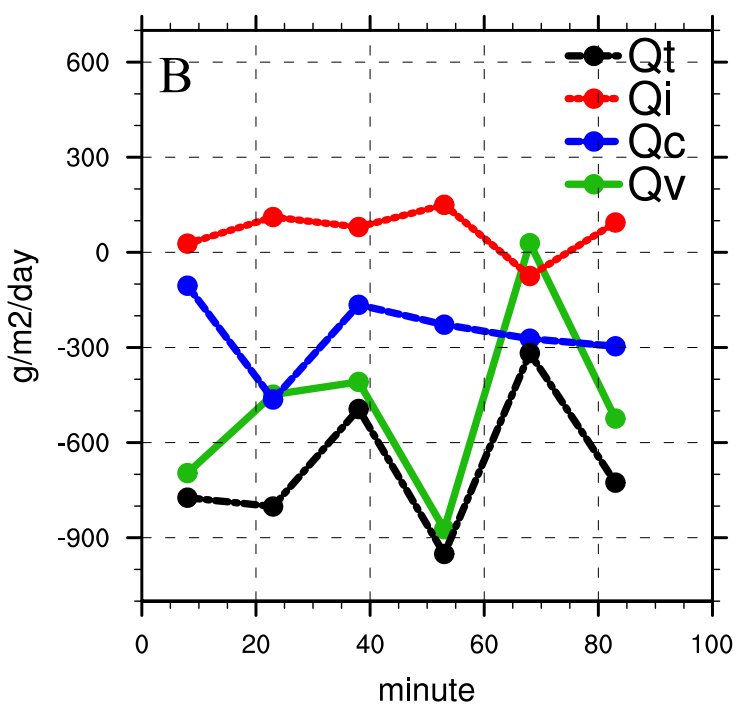

Fig. 12. Time series of 15 -min averaged water content tendencies from 20:00Z-21:29 Z in upper entrainment zone (A) and mixed layer (B), in units of $\mathrm{g} \mathrm{m}^{-2} \mathrm{day}^{-1}$.

zonal and meridional boundaries of the domain, with $x_{e}-$ $x_{w}=y_{n}-y_{s}=6.5 \mathrm{~km}$. The notation below (6) indicates abbreviations used for the advection terms. The difference between total tendency and the sum of advective and microphysical tendencies is equal to subgrid-scale mixing plus diffusion, which are not represented in (4). This difference will be referred to as the residual (RES) hereafter. The residual is calculated using instantaneous total, advective, and microphysical tendencies output every minute. Layer budgets are calculated by vertically integrating (4) and (6) from $0.82-$ $1.24 \mathrm{~km}$ for the mixed layer and $1.24-1.3 \mathrm{~km}$ for the upper entrainment zone.
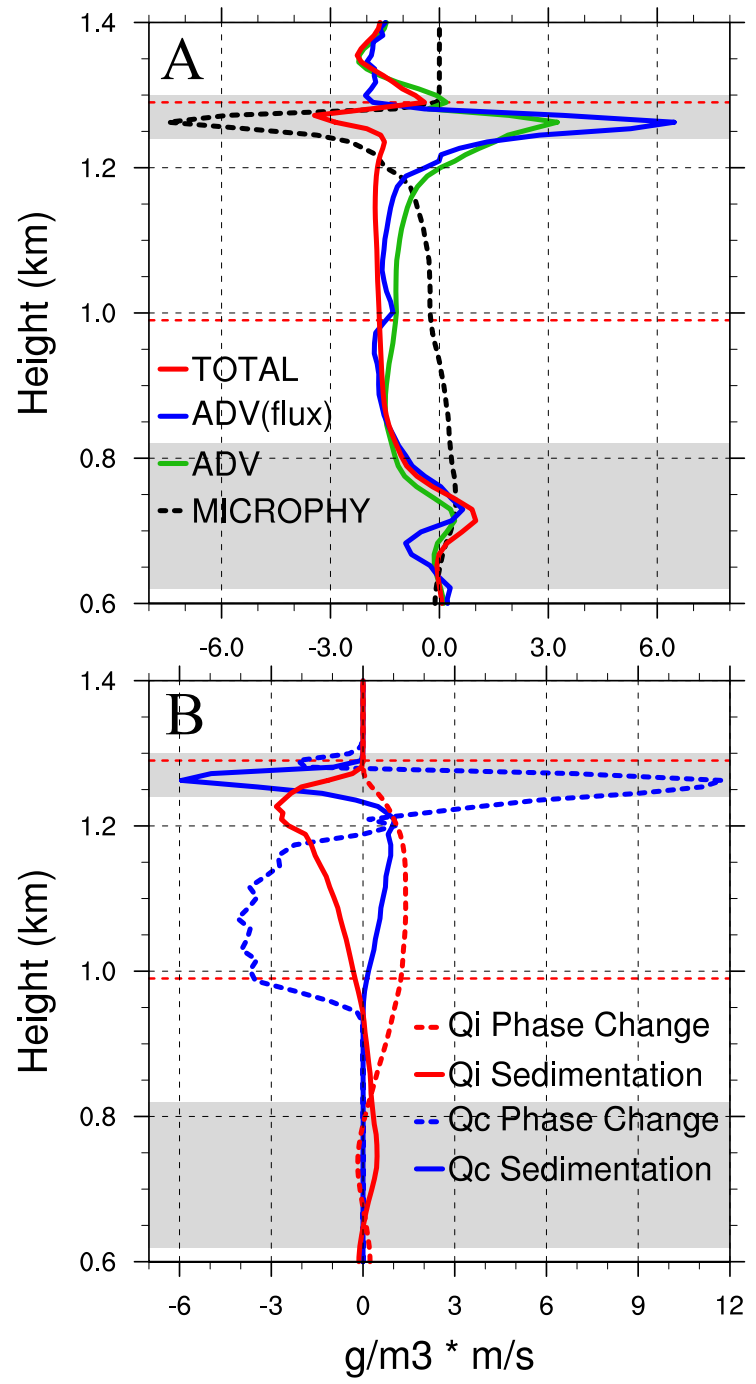

Fig. 13. (A) Processes that contribute to 15 -min averaged total water content tendencies above the surface layer for the square box, in units of $\mathrm{g} \mathrm{m}^{-3} \mathrm{day}^{-1}$. Note that the net contribution due to microphysics for total water (MICROPHY) is equal to sedimentation, as condensational terms cancel. "ADV(flux)" is total flux estimated using Eq. (6). "ADV" is total advection output from the model. "TOTAL" is total water tendency. Entrainment zones indicated with gray shading. (B) Cloud liquid water and ice microphysical tendencies divided into contributions due to phase change and sedimentation, in units of $\mathrm{g} \mathrm{m}^{-3} \mathrm{day}^{-1}$. Cloud layer top and base indicated by red dashed lines.

Total water content tendencies above the base of the lower entrainment zone are plotted in Figs. 13 and 14. The net contribution of microphysical processes to the total water tendency is equal to sedimentation because phase-change terms cancel for total water. Since total, advective and microphysical tendency terms averaged over every time step were not available for analysis, Fig. 13a shows these tendency terms averaged over instantaneous fields output every minute. The ADV(flux) tendency term is the sum of 

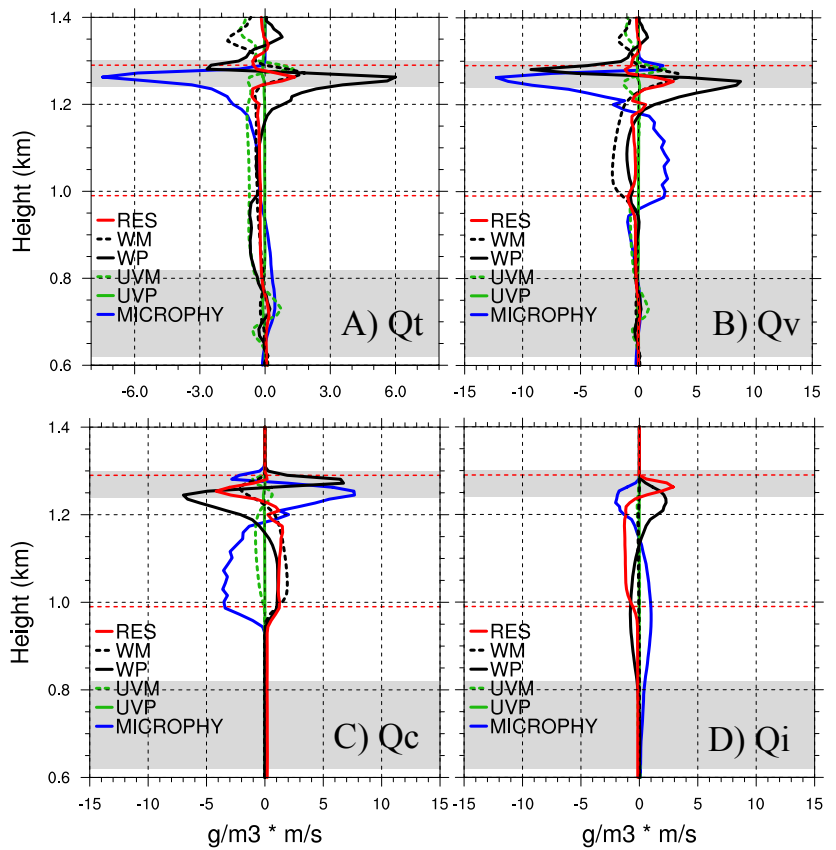

Fig. 14. Processes that contribute to 15 -min averaged water content tendencies above the surface layer for the square box, in units of $\mathrm{g} \mathrm{m}^{-3}$ day $^{-1}$. Note net contribution due to microphysics for total water in (A) is equal to sedimentation, as condensational terms cancel. The residual is equal to subgrid scale mixing plus diffusion. Mean advection terms (denoted with WM, UVM) are calculated by horizontally averaging tendencies. Horizontal eddy advection (UVP) is calculated as the divergence of fluxes across the domain. Vertical eddy advection (WP) is the divergence of the vertical eddy flux. Note change in scale in (A). Entrainment zones indicated with gray shading. (A) Total water. (B) Water vapor. (C) Cloud liquid water. (D) Cloud ice water. Cloud layer top and base indicated by red dashed lines.

the advective tendencies in Eq. (6), while ADV is the exact advective tendency output from the model. The difference between the ADV and ADV(flux) curves is an estimate of the error in the post-processed advective tendencies relative to tendencies output from the model, and is generally small throughout the profile.

At the top boundary of the upper entrainment zone there is a decrease in total water of $-1 \mathrm{~g} \mathrm{~m}^{-3}$ day $^{-1}$ (Fig. 13a), with the dominant term being the vertical turbulent advection of water vapor (WP in Fig. 14a, b). Within the entrainment zone there is down gradient mixing of both water vapor and cloud liquid water such that turbulent vertical advection increases (decreases) cloud liquid water (water vapor) above $1.27 \mathrm{~km}$ and opposite below (Fig. 14b, c). Sedimentation, which is the microphysics term in Figs. 13a and 14a because phase transitions conserve total water, is a maximum within the upper entrainment zone due to the fallout of primarily liquid water and some ice into the top of the mixed layer. Thus, one significant process for moving water
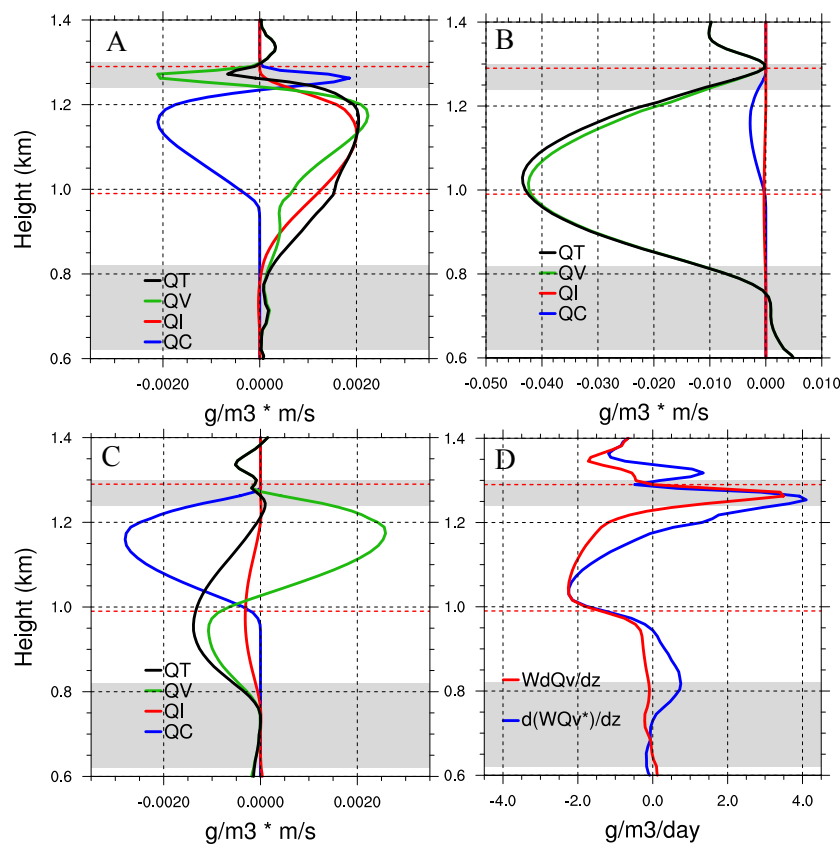

Fig. 15. Horizontally and temporally averaged vertical water content fluxes, in units of $\mathrm{g} \mathrm{m}^{-3} \mathrm{~m} \mathrm{~s}^{-1}$. Entrainment zones indicated with gray shading. (A) Eddy fluxes. (B) Mean fluxes. (C) Mean fluxes as in (B) except mean water vapor vertically averaged between $0.7-1.4 \mathrm{~km}$ is removed before calculating mean water vapor flux. (D) Vertical derivative of modified mean water vapor flux $\left(\mathrm{WQv}^{*}\right)$ from (C) compared to water vapor tendency due to advection by mean vertical velocity (WM in Fig. 14b). Cloud layer top and base indicated by red dashed lines.

from the inversion into the mixed layer is liquid condensation in the entrainment zone (Fig. 14c) and its sedimentation (Fig. 13b). While ice sedimentation into the mixed layer is relatively large, most of this ice is actually mixed upward into the entrainment zone by turbulent eddies while little is actually formed there (Figs. 13b, 14d). At the lower boundary of the upper entrainment zone a positive (negative) tendency of water vapor (cloud liquid water) due to vertical turbulent fluxes is balanced closely by condensation/evaporation and sedimentation.

From $1.1 \mathrm{~km}$ to the top of the mixed layer, total water tendencies due to sedimentation and eddy vertical advection tend to cancel (Fig. 14a), such that the total mixed-layer tendency is a drying of approximately $-2 \mathrm{~g} \mathrm{~m}^{-3}$ day $^{-1}$ that is essentially independent of height (Fig. 13a). Within the lower cloudy portion of the mixed layer, the largest tendency term is the increase (decrease) in water vapor (cloud liquid water) due to evaporation.

Figure $15 \mathrm{a}, \mathrm{b}$ shows vertically resolved turbulent $\left(\overline{w^{\prime} q_{*}^{\prime}}\right)$ and mean $\left(\overline{w q_{*}}\right)$ water fluxes, respectively. In Fig, $15 \mathrm{~b}$ it is clearly seen that $\overline{w q_{\mathrm{v}}}$ is an order of magnitude larger than $\overline{w q_{\mathrm{c}}}$ and $\overline{w q_{\mathrm{i}}}$. This is due to large vertical mass fluxes $\left(\overline{q_{\mathrm{v}}} \partial \bar{w} / \partial z\right)$ that do not contribute to vertical mean advective 
tendencies of water vapor $\left(\bar{w} \partial \overline{q_{\mathrm{v}}} / \partial z\right.$, WM in Fig. $\left.14 \mathrm{~b}\right)$. Figure $15 \mathrm{~b}$ indicates that there is a mean larger-scale (larger than the $6.5 \times 6.5 \mathrm{~km}$ square domain used in the analysis) circulation within the mixed layer and upper entrainment zone producing a horizontal mass flux into the entrainment zone and upper mixed layer, a downward mass flux within the mixed layer, and a horizontal mass flux out of the lower mixed layer. The largest vertical mean mass flux is located near the cloud base $(\sim 1 \mathrm{~km})$, which suggests that this larger-scale circulation is driven by the cloud layer itself. In order to isolate the part of $\overline{w q_{\mathrm{v}}}$ that contributes to $\bar{w} \partial \overline{q_{\mathrm{v}}} / \partial_{z}$, the mean water vapor used to calculate $\overline{w q_{\mathrm{v}}}$ in Fig. $15 \mathrm{~b}$ is modified by subtracting its vertical average between $0.7-1.4 \mathrm{~km}$, thereby using only the vertical perturbations of water vapor in the mean flux calculations. This modified mean water vapor flux better represents the smaller-scale contribution to the vertical water vapor mass flux $\overline{w q_{\mathrm{v}}}$, and is much smaller in magnitude (Fig. 15c) than that found in Fig. 15b. Figure 15d shows the extent to which the mass flux contribution has been eliminated from the modified $\overline{w q_{\mathrm{v}}}$ by comparing $\bar{w} \partial \overline{q_{\mathrm{v}}} / \partial_{z}$ to $\partial \overline{w q_{\mathrm{v}}} / \partial_{z}$ from Fig. 15c. Differences between the two curves in Fig. $15 \mathrm{~d}$ indicate that $\overline{w q_{\mathrm{v}}}$ is overestimated near the top and bottom of the mixed layer.

Comparing Fig. 15a and c, it is seen that at the top of the upper entrainment zone both turbulent and mean vertical fluxes are essentially zero. Therefore, the decrease in total water by turbulent eddies in the upper part of the entrainment zone is primarily due to a downward transport of water vapor from below the top of the upper entrainment zone. In addition, the turbulent flux of total water at the mixed-layer top is positive, primarily due to positive fluxes of cloud liquid water and ice. The mean flux of total water is approximately equal to zero at the mixed-layer top, with a positive mean flux of vapor balancing a negative mean flux of cloud water (Fig. 15c). The slightly negative total water flux at the base of the mixed layer is primarily due to a negative flux of water vapor by the mean flow, which is partially offset by a small positive turbulent vapor flux. However, its magnitude is about $-0.0003 \mathrm{~g} \mathrm{~m}^{-2} \mathrm{~s}^{-1}$, which is an order of magnitude smaller than the vertical flux due to ice sedimentation at the mixed-layer base (results not shown). Thus, the net flux of water through the mixed-layer base is primarily 16 due to sedimentation and not to mean or turbulent vertical motions.

\subsubsection{Layer budgets}

Following Curry et al. (1988), we calculate vertically integrated water content budgets in the mixed layer and upper entrainment zone with Eq. (4 and 6). Table 3 shows the contribution of advection and microphysics to water content tendencies in the upper entrainment zone. Note that the microphysics term (MICROPHY) in total water tendencies is equal to sedimentation. There is a net decrease in total water in the upper entrainment zone as sedimentation out is greater than net advection in. The entrainment zone loses $-99 \mathrm{~g} \mathrm{~m}^{-2} \mathrm{day}^{-1}$ on average over the 90 -min period, although this rate varies from -30 to $-200 \mathrm{~g} \mathrm{~m}^{-2} \mathrm{day}^{-1}$ for 15 -min averages (Fig. 12). This net loss of total water is primarily due to a net cloud liquid water gain of $100 \mathrm{~g} \mathrm{~m}^{-2}$ day $^{-1}$ offset by a water vapor loss of $203 \mathrm{~g} \mathrm{~m}^{-2} \mathrm{day}^{-1}$. Because water vapor has no sedimentation, the $379 \mathrm{~g} \mathrm{~m}^{-2} \mathrm{day}^{-1}$ of water vapor loss due to microphysics implies a liquid water gain of $379 \mathrm{~g} \mathrm{~m}^{-2}$ day $^{-1}$ due to condensation, assuming minimal ice formation. The net $q_{\mathrm{c}}$ gain of $208 \mathrm{~g} \mathrm{~m} \mathrm{day}^{-1}$ from microphysics then implies cloud liquid water sedimentation of $30 \mathrm{~g} \mathrm{~m}^{-2} \mathrm{day}^{-1}$ from the upper entrainment zone. Mean and eddy vertical advection produce a $100 \mathrm{~g} \mathrm{~m}^{-2}$ day $^{-1}$ loss of $q_{\mathrm{c}}$, but a $181 \mathrm{~g} \mathrm{~m}^{-2}$ day $^{-1}$ gain of water vapor. There is a relatively neutral ice tendency in this zone, as the $71 \mathrm{~g} \mathrm{~m}^{-2}$ day $^{-1}$ gain due to lofting by eddy vertical advection from the mixed layer is offset by sedimentation. A small amount of cloud ice is produced through phase changes (deposition, freezing; Fig. 13b). Hence, the water budget in the entrainment zone consists of a net loss of total water primarily due to liquid water condensation and a loss of $72 \%$ of this liquid water to the mixed layer through sedimentation and vertical advection. The vertical profiles (Fig. 14) additionally show that water vapor is primarily redistributed from the top of the entrainment zone to the base of the entrainment zone by vertical mixing due to resolved eddies.

Table 4 shows the contributions of advection and microphysics to water content tendencies integrated over the mixed layer from $0.82-1.24 \mathrm{~km}$. The mixed layer loses $-696 \mathrm{~g} \mathrm{~m}^{-2} \mathrm{day}^{-1}$ of water averaged over the 90 -min period. The rate of total water depletion from the mixed layer varies from -300 to $-950 \mathrm{~g} \mathrm{~m}^{-2} \mathrm{day}^{-1}$ over the 15 -min periods, while liquid water loss is $-281 \mathrm{~g} \mathrm{~m}^{-2} \mathrm{day}^{-1}$ and ranges from -100 to $-450 \mathrm{~g} \mathrm{~m}^{-2} \mathrm{day}^{-1}$. The mixed layer is $7 \mathrm{X}$ deeper than the upper entrainment zone and loses $7 \mathrm{X}$ as much total water, with $43 \%$ of this loss due to horizontal advection. Mean vertical advection, sedimentation, and upward transport by eddies each contribute between $15 \%$ and $21 \%$ of this loss. In the cloudy portion of the mixed layer, evaporation and collection reduces the cloud liquid water at a rate of $-523 \mathrm{~g} \mathrm{~m}^{-2} \mathrm{day}^{-1}$, while ice and water vapor both increase through these processes (Fig. 13b). A substantial amount of the water vapor increase is converted to cloud ice through deposition (i.e., the Bergeron process). There is also a substantial loss $\left(-136 \mathrm{~g} \mathrm{~m}^{-2}\right.$ day $\left.^{-1}\right)$ of cloud liquid water due to mean horizontal advection and loss of water vapor due to mean vertical advection (Fig. 14b). Within the cloud in the mixed layer, sedimentation produces decreases of ice and smaller increases in liquid water (Fig. 13b). Below cloud base within the mixed layer, ice amounts increase weakly due to both sedimentation and vapor deposition, while weak losses of water vapor occur from all terms, including mean horizontal advection (Fig. 14b).

Considering total water alone, the cloud should eventually dissipate due to net loss of water in both the upper 
Table 3. Mean ( \pm one standard deviation) contribution of advection and microphysics to time and horizontally averaged water content tendencies in the upper entrainment zone, in units of $\mathrm{g} \mathrm{m}^{-2}$ day ${ }^{-1}$. Advection by the mean flow is calculated from 15-min averaged fields. Eddies are defined as deviations from the 15-min averages. Total* is the sum of advection terms plus microphysics and is not exactly equal to total tendency due to errors incurred by calculating the advection terms offline (see discussion of Fig. 13).

\begin{tabular}{lrrrrrr}
\hline Upper Entrainment Zone & UVM & UVP & WM & WP & MICROPHY & Total $^{*}$ \\
\hline Total Water & $-11 \pm 45$ & $-6 \pm 3$ & $34 \pm 54$ & $117 \pm 14$ & $-233 \pm 10$ & $-99 \pm 85$ \\
Cloud Water & $-5 \pm 77$ & $-3 \pm 4$ & $-78 \pm 33$ & $-22 \pm 64$ & $208 \pm 29$ & $100 \pm 152$ \\
Water Vapor & $-2 \pm 111$ & $-3 \pm 6$ & $113 \pm 88$ & $68 \pm 45$ & $-379 \pm 28$ & $-203 \pm 226$ \\
Cloud Ice & $-4 \pm 3$ & $+0 \pm 0$ & $-0 \pm 1$ & $71 \pm 16$ & $-62 \pm 13$ & $5 \pm 3$ \\
\hline
\end{tabular}

Table 4. The same as Table 3 except for the mixed layer budget.

\begin{tabular}{lrrrrrr}
\hline Mixed Layer & UVM & UVP & WM & WP & MICROPHY & Total* $^{*}$ \\
\hline Total Water & $-301 \pm 192$ & $-8 \pm 6$ & $-141 \pm 74$ & $-101 \pm 25$ & $-145 \pm 49$ & $-696 \pm 256$ \\
Cloud Water & $-136 \pm 110$ & $-6 \pm 3$ & $363 \pm 158$ & $21 \pm 64$ & $-523 \pm 169$ & $-281 \pm 137$ \\
Water Vapor & $-140 \pm 295$ & $3 \pm 4$ & $-484 \pm 217$ & $-56 \pm 33$ & $222 \pm 185$ & $-455 \pm 341$ \\
Cloud Ice & $-24 \pm 73$ & $-5 \pm 5$ & $-21 \pm 14$ & $-65 \pm 13$ & $156 \pm 23$ & $41 \pm 87$ \\
\hline
\end{tabular}

entrainment zone and mixed layer. Transport of water vapor into the lower part of the upper entrainment zone is large enough to cause continual liquid condensation that is transported or sedimented downward into the mixed layer. In the mixed layer, loss due to microphysics exceeds this injection of cloud liquid water from the entrainment zone, resulting in a continual net loss of cloud liquid water.

\subsection{Downdraft and updraft averages}

Vapor, liquid, and ice water tendencies averaged over incloud updrafts and downdrafts separately in the square domain and temporally averaged over the 90-min period are plotted in Fig. 16. Also shown in Fig. 16 are mean vertical velocity and $\theta_{\mathrm{e}}$ profiles averaged over downdrafts and updrafts separately. Downdrafts are defined as gridpoints where minimum vertical velocity within the cloud layer is less than $-30 \mathrm{~cm} \mathrm{~s}^{-1}$ (see Fig. 16c). Updrafts are defined as gridpoints where maximum vertical velocity within the cloud layer is greater than $20 \mathrm{~cm} \mathrm{~s}^{-1}$ (see Fig. 16d). Out of 16900 gridpoints, approximately $3000-4000$ gridpoints at a given time are classified as downdrafts and 4000-5000 gridpoints are classified as updrafts. These numbers are consistent with cloud dynamics forced by radiative cooling at cloud top, which result in narrower yet stronger downdrafts relative to updrafts. Vertical velocity above the cloud layer is approximately $-0.4 \mathrm{~cm} \mathrm{~s}^{-1}$ in averages over updrafts and downdrafts (Fig. 11b). Figure 16a and b show the contributions of cloud water, cloud ice, and water vapor to downdraft and updraft total water tendencies, respectively. It is clearly seen that within the upper entrainment zone, the decrease in water vapor and increase in cloud liquid water seen in the total do- main averages (Fig. 11) only occur above downdrafts. Above updrafts, the opposite, yet somewhat weaker, tendencies are present. In downdrafts, mixed-layer cloud water decreases while water vapor, ice, and total water increase. Compensating effects occur in updrafts, where mixed-layer cloud liquid water increases (within the cloud) while a decrease of water vapor, ice, and total water occurs throughout. Note that the base of cloud liquid water increases in the updrafts occurs above the base of cloud liquid water decreases in the downdrafts, suggesting a modulation of cloud base height by vertical motions.

Tendencies in water vapor and cloud liquid water in updrafts and downdrafts are due to compensating large microphysics and advection tendencies that sum to a smaller residual (see Fig. 17). Within the cloud layer, in downdrafts, opposite vertical gradients of cloud liquid water and water vapor cause an increase in cloud liquid water and decrease in water vapor by vertical advection, with the cloud liquid water then decreasing by evaporating and thereby increasing water vapor. In this process the microphysical tendencies are slightly dominant, resulting in small residuals of opposite sign for liquid and vapor (Fig. 17a, c). Approximately the opposite is true in updrafts, although advective and microphysical tendency magnitudes are smaller and more nearly balanced leading to smaller total tendencies of opposite signs relative to downdrafts (Fig. 17 b, d). Ice tendencies are dominated by advective tendencies in both updrafts and downdrafts, while sedimentation and total microphysics terms are quite small (Fig. 17 e, f).

It is important to note that condensation occurs in the upper entrainment zone in both updrafts and downdrafts (Fig. 17a, b, c, d). This process of "radiative encroachment," 

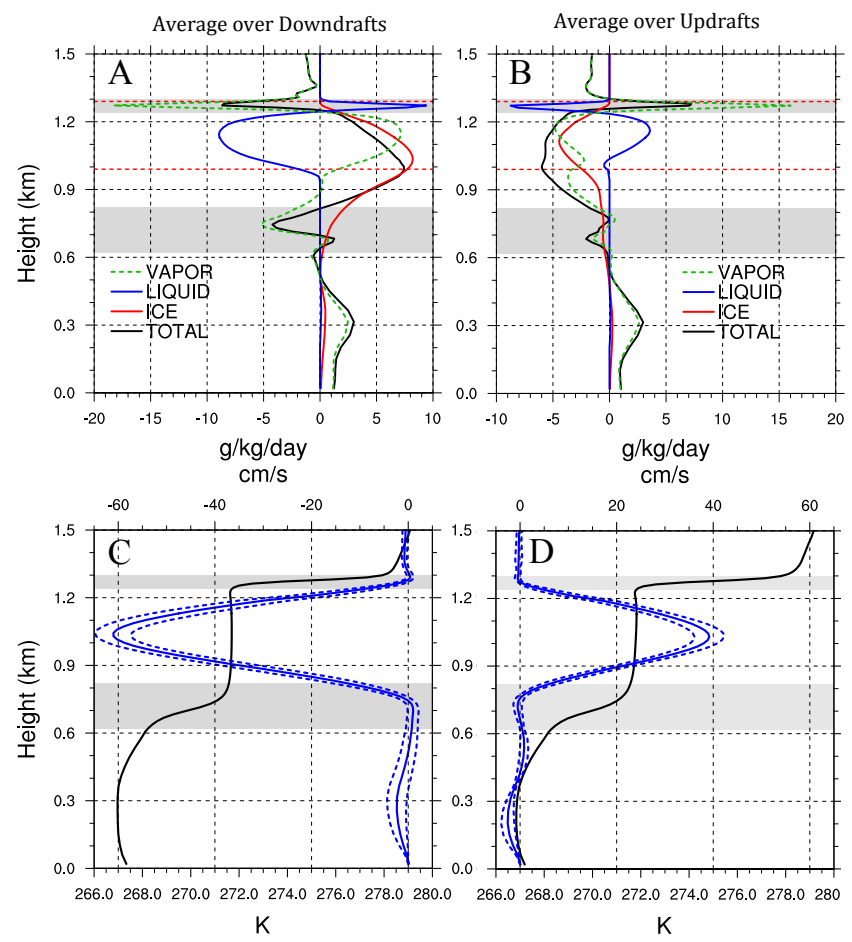

Fig. 16. Average profiles in downdrafts (left side; A, C) and updrafts (right side; $\mathbf{B}, \mathbf{D}$ ) in the square box of liquid, vapor, ice and total water mixing ratio tendencies $\left(\mathbf{A}, \mathbf{B} ; \mathrm{g} \mathrm{kg}^{-1} \mathrm{day}^{-1}\right)$ and mean resolved vertical velocity (blue, \pm one standard deviation of onemin averages dashed; $\mathrm{cm} \mathrm{s}^{-1}$ ) and equivalent potential temperature (black; K) (C, D). Entrainment zones indicated with gray shading. Cloud layer top and base indicated by red dashed lines in $(\mathbf{A}, \mathbf{B})$.

or forcing of direct condensation by cooling that cannot be balanced by convection, is a process that contributes to the positive cloud water tendency in the upper entrainment zone (Fig. 11). This process occurs because of the specific humidity inversion that is coincident with the temperature inversion. We also emphasize that this radiative condensational processes, occurring above both updrafts and downdrafts, is quite different from the adiabatic cooling process simultaneously producing condensation in the mixed-layer updrafts as seen in Fig. 17b. Lastly, while cloud liquid condensation and evaporation occur in mixed-layer updrafts and downdrafts, respectively, deposition on cloud ice occurs in both updrafts and downdrafts (i.e., the difference between sedimentation and microphysics terms in Fig. 17 e, f). Slightly more ice deposition occurs in updrafts.

\section{Summary and discussion}

In this paper we use high-resolution nested LES simulations to quantify the processes involved in the maintenance and persistence of a single-layer, decoupled AMPS that was observed near Barrow, Alaska, during ISDAC on 8 April 2008.

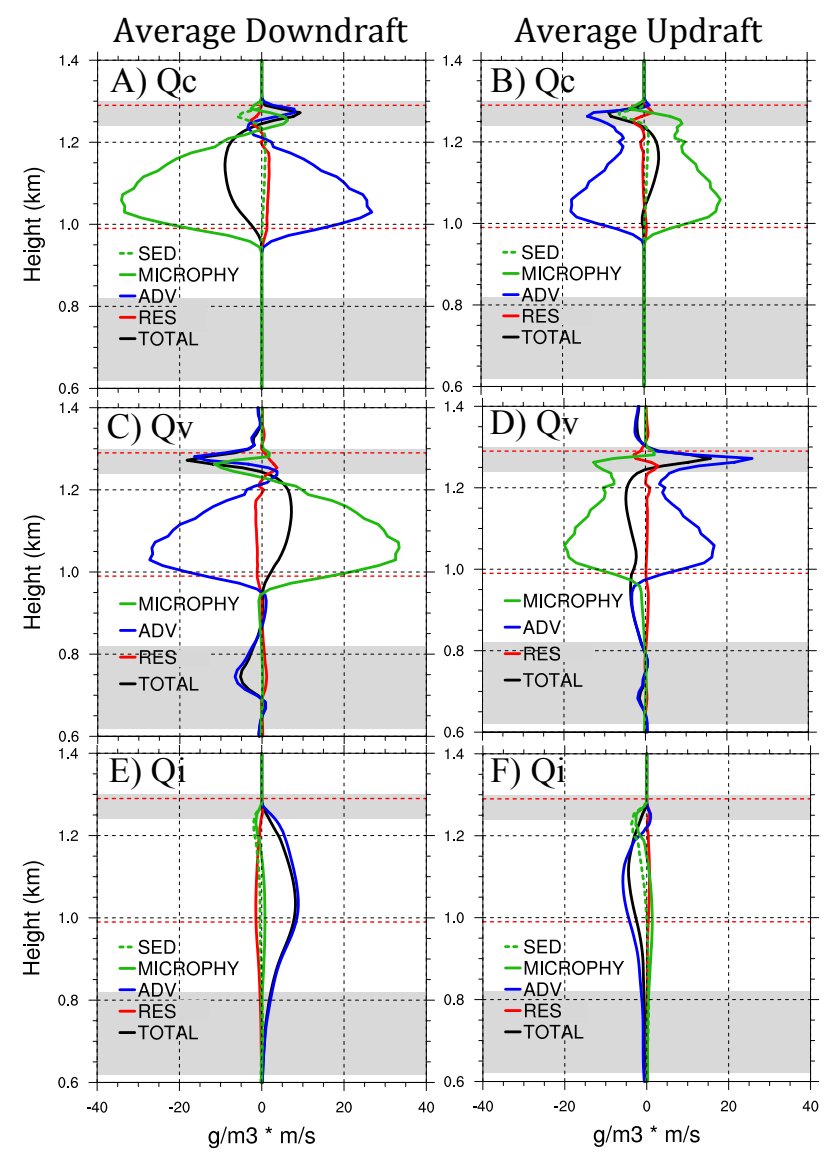

Fig. 17. Processes that contribute to water content tendencies between $0.6-1.4 \mathrm{~km}$ averaged over downdrafts and updrafts, in units of $\mathrm{g} \mathrm{m}^{-3} \mathrm{day}^{-1}$. (A) Cloud liquid water tendencies in downdrafts. (B) Cloud liquid water tendencies in updrafts. (C) Water vapor tendencies in downdrafts. (D) Water vapor tendencies in updrafts. (E) Cloud ice water tendencies in downdrafts. (F) Cloud ice water tendencies in updrafts. The contribution of sedimentation to the microphysical tendencies is shown with a green dashed line in (A), (B), (E), (F). Entrainment zones indicated with gray shading. Cloud layer top and base indicated by red dashed lines.

A mean temperature inversion of $5 \mathrm{~K}$ and humidity inversion of $0.4 \mathrm{~g} \mathrm{~kg}^{-1}$ with a base at $1.2 \mathrm{~km}$ was simulated in the LES at $20 \mathrm{Z}$, similar to the radiosounding taken at $17: 34 \mathrm{Z}$ that showed a mean temperature inversion of $4 \mathrm{~K}$ and humidity inversion of $0.5 \mathrm{~g} \mathrm{~kg}^{-1}$ with a base at $1.1 \mathrm{~km}$.

The model-simulated atmosphere below $1.3 \mathrm{~km}$ is composed of five distinct layers; a turbulent surface layer, a stable layer from $200-600 \mathrm{~m}$, a lower entrainment zone between $0.62-0.82 \mathrm{~km}$, a cloud-driven mixed layer between 0.82 $1.24 \mathrm{~km}$, and a (partly) cloudy upper entrainment zone between $1.24-1.30 \mathrm{~km}$. The inversion height remains at $1.3 \mathrm{~km}$ over the $90 \mathrm{~min}$ analysis period while the mixed layer base moves downward at a rate of $50 \mathrm{~m} \mathrm{~h}^{-1}$. Different from subtropical stratocumulus, cloud liquid water in these Arctic stratocumulus extends into the inversion layer. 
Longwave radiative cooling peaks within the temperature inversion and upper entrainment zone but also extends $80 \mathrm{~m}$ down into the mixed layer, coincident with turbulent vertical potential temperature fluxes. The average potential temperature tendency due to longwave cooling at the mixed-layer top is approximately $-80 \mathrm{~K} \mathrm{day}^{-1}$. There is a relatively uniform net cooling of $-4 \mathrm{Kday}^{-1}$ within the mixed layer.

Buoyancy, shear, pressure transport, and TKE transport make significant contributions to the vertical distribution of TKE tendencies. In the upper entrainment zone, TKE production is dominated by pressure transport and shear but limited by buoyancy. At the top of the mixed layer shear is the dominant production term. Moving down into the mixed layer, shear remains important along with buoyancy production. TKE is advected downward to the base of the mixed layer where TKE production by other terms is small. All production terms become small below the mixed layer, effectively decoupling the cloud from the lower troposphere and surface.

At the top boundary of the upper entrainment zone there is a decrease in total water of $-1 \mathrm{~g} \mathrm{~m}^{-3}$ day $^{-1}$ primarily due to eddy vertical advection of water vapor. Within the entrainment zone there is down gradient mixing by turbulent eddies that causes an upward (downward) transport of cloud liquid water (water vapor) above the liquid water maximum at the base of the upper entrainment zone (top of the mixed layer), and oppositely below. In terms of total water, entrainment moistens the cloud layer in the lower part of the upper entrainment zone (Fig. 14b). The increase (decrease) in water vapor (cloud liquid water) due to turbulent fluxes in the lower part of the entrainment zone is closely balanced by a decrease (increase) by condensation and liquid sedimentation, with sedimentation exceeding advection of total water by $2 \mathrm{~g} \mathrm{~m}^{-3} \mathrm{day}^{-1}$ at the lower boundary. The upper entrainment zone loses an average of $-99 \mathrm{~g} \mathrm{~m}^{-2}$ day $^{-1}$ of total water to the mixed layer.

The mixed layer loses total water at a rate of $-696 \mathrm{~g} \mathrm{~m}^{-2} \mathrm{day}^{-1}$. This tendency is primarily due to horizontal advection by the mean flow, while $-387 \mathrm{~g} \mathrm{~m}^{-2}$ day $^{-1}$ of total water loss is approximately equally divided between losses due to turbulent vertical fluxes, mean vertical advection, and sedimentation (Table 4). Neglecting tendencies due to mean horizontal wind, net loss of cloud liquid water is due to microphysical processes that are partially offset by mean vertical advection at the mixed-layer top. Turbulent and mean fluxes of total water at the mixed-layer top are positive and larger than fluxes at the base.

The average loss of cloud water from the upper entrainment zone plus mixed-layer system is $-181 \mathrm{~g} \mathrm{~m}^{-2} \mathrm{day}^{-1}$, or $7.5 \mathrm{~g} \mathrm{~m}^{-2} \mathrm{~h}^{-1}$. However, over this 90 -min period the upper entrainment zone gains cloud liquid water while continually losing total water. This is due to the continuous source of water vapor provided to the cloud layer by turbulent down gradient mixing and condensation forced by radiative cooling that cannot be balanced by convection. For an initial liquid water path of $50 \mathrm{~g} \mathrm{~m}^{-2}$, assuming no change in the dynamical balance, a cloud could persist at this rate for $6.7 \mathrm{~h}$. The net loss of cloud water is only $23 \%$ of the loss of total water, i.e. the mixed layer plus entrainment zone is losing vapor 3.5 times faster than it is losing cloud liquid water.

Interestingly, mean subsidence above the upper entrainment zone is of the same order as mean subsidence in subtropical cloud-topped boundary layers (see Wood and Bretherton, 2004) and other LES simulations of AMPS (see Klein et al., 2009). However, mean subsidence goes to zero at the upper entrainment zone top, resulting in no net vertical flux of water into the upper entrainment zone. Essentially all vertical transport of water into the mixed layer initiates in the upper entrainment zone.

This study has shown that sedimentation plays a dominant role in vertical transport and depletion of water from a decoupled AMPS cloud system. This sedimentation is due to both gravitational settling of liquid water in the mixed layer and continuous precipitation of ice out of the mixed layer. In this model study, ice mass production might be underestimated relative to retrievals and aircraft observations (although there is uncertainty to these comparisons). It is unclear what impact greater ice production would have on the simulation. For example, in subtropical boundary layers, sedimentation removes water near cloud top resulting in less entrainment of dry, warm air and a more persistent cloud (Ackerman et al., 2004; Bretherton et al., 2007). Sedimentation in AMPS at cloud top may have the opposite effect, as entrainment acts to further moisten the cloud. Also, production of more ice would cause more condensational heating to balance longwave cooling and thereby modify vertical motions in the mixed layer. In addition, more ice production may cause more moistening of the surface layer.

In both updrafts and downdrafts, vertical velocity above the cloud layer is approximately $-0.4 \mathrm{~cm} \mathrm{~s}^{-1}$. The decrease in water vapor and increase in cloud liquid water in the upper entrainment zone occurs primarily above mixed-layer downdrafts. Above mixed-layer updrafts, the opposite occurs. Similar opposing tendencies among the water phases in updrafts and downdrafts are seen in the mixed layer. Of primary importance is that condensation occurs within the upper entrainment zone above both updrafts and downdrafts due to diabatic radiative cooling, while condensation within the mixed layer occurs only in updrafts due to adiabatic cooling.

Results of this nested LES study form a relatively simple conceptual model of decoupled AMPS where the essential structures and processes are:

1. A humidity inversion at cloud top provides a weak source of moisture to the cloud layer via entrainment caused by cloud-generated turbulence. This continual down gradient transport of water vapor into the cloud layer supports its persistence and represents a positive feedback. 
2. The primary and necessary source of energy for the system is longwave radiative cooling at, and near, cloud top. Radiative cooling does at least two things: (1) Forces direct condensation in non-buoyant parcels near cloud top that are inside the temperature and moisture inversions; (2) Forces turbulence and buoyancydriven overturning of parcels within a cloudy mixed layer, with additional condensation occurring in updrafts.

3. Cloud ice depositional growth occurs primarily in the mixed layer in both updrafts and downdrafts, although slightly more in the latter.

4. The primary transport of total water from the entrainment zone into the mixed layer is via sedimentation of liquid water. Ice precipitation is the primary net sink of condensed mass from the cloudy mixed layer.

We speculate that collapse of the system occurs when the moisture source above the cloud is exhausted (i.e., supply rate of moisture due to entrainment is less than the sedimentation rate of condensate out of the cloud mixed layer for a long enough time) and/or condensed liquid water drops below its threshold for efficient emission causing radiative cooling, and therefore buoyant overturning, to diminish (see Morrison et al., 2011 for a discussion on this point).

We acknowledge that, while consistent with many observations and past studies, the budgets and processes described here are primarily based on the model representation of this one AMPS case. Hence, model configuration and physics may have significant impacts on the results. A deficiency in our simulations (and in many AMPS simulations) is the apparent underestimation of cloud ice. Future observational and modeling work should obtain detailed observations to verify the processes described here, especially those within the upper entrainment zone and the upper portion of the mixed layer, improve model representations, explore the generality of these results, and attempt to understand the processes modulating the coupling of AMPS with surface forcing.

\section{Supplementary material related to this article is available online at: http://www.atmos-chem-phys.net/11/10127/2011/ acp-11-10127-2011-supplement.pdf.}

Acknowledgements. This research was supported by the Office of Science (BER), US Department of Energy (DE-FG01-05ER63965) and National Science Foundation (ARC-1023366). Any opinions, findings and conclusions or recommendations expressed in this material are those of the authors and do not necessarily reflect the views of the sponsors. HM acknowledges partial funding from US DOE ARM DE-FG02-08ER64574, and the NSF Science and Technology Center for Multiscale Modeling of Atmospheric Processes (CMMAP), managed by Colorado State University under cooperative agreement ATM-0425247. Observational data used in this study were provided by the Department of Energy's Atmospheric Radiation Measurement Program. ECMWF datasets used as boundary conditions for the model simulations were downloaded from the Research Data Archive, which is maintained by the Computational and Information Systems Laboratory at the National Center for Atmospheric Research. The National Center for Atmospheric Research is sponsored by the National Science Foundation.

Edited by: T. Garrett

\section{References}

Abdul-Razzak, H. and Ghan, S. J.: A parameterization of aerosol activation 2. Multiple aerosol types, J. Geophys. Res., 105, 6837-6844, 2000.

Ackerman, A. S., Kirkpatrick, M. P., Stevens, D. E., and Toon, O. B.: The impact of humidity above stratiform clouds on indirect aerosol climate forcing, Nature, 432, 1014-1017, 2004.

Albrecht, B. A., Penc, R. S., and Schubert, W. H.: An observational study of cloud-topped mixed layers, J. Atmos. Sci., 42, 800-822, 1985.

Albrecht, B. A., Jensen, M. P., and Syrett, W. J.: Marine boundary layer structure and fractional cloudiness, J. Geophys. Res., 100, 209-214, 1995.

Avramov, A., Ackerman, A. S., Fridlind, A. M., van Diedenhoven, B., Botta, G., Aydin, K., Verlinde, J., Korolev, A., Strapp, J. W., McFarquhar, G. M., Jackson, R., Brooks, S. D., Glen, A., and Wolde, M.: Towards ice formation closure in Arctic mixed-phase boundary layer clouds during ISDAC, J. Geophys. Res., in press, doi:10.1029/2011JD015910, 2011.

Bretherton, C. S., Blossey, P. N., and Uchida, J.: Cloud droplet sedimentation, entrainment efficiency, and subtropical stratocumulus albedo, Geophys. Res. Lett., 34, L03813, doi:10.1029/2006GL027648, 2007.

Brost, R. A., Wyngaard, J. C., and Lenschow, D. H.: Marine stratocumulus layers. Part II: Turbulence budgets, J. Atmos. Sci., 39, 818-836, 1982.

Chen, F. and Dudhia, J.: Coupling an advanced land-surface/ hydrology model with the Penn State/ NCAR MM5 modeling system. Part I: Model description and implementation, Mon. Weather Rev., 129, 569-585, 2001.

Collins, W. D., Rasch, P. J., Boville, B. A., Hack, J. J., Mccaa, J. R., Williamson, D. L., and Briegleb, B. P.: Description of the NCAR Community Atmosphere Model (CAM 3.0), NCAR Technical Note, NCAR/TN-464+STR, 226 pp., 2004.

Curry, J. A., Ebert, E. E., and Herman, G. F.: Mean and turbulence structure of the summertime Arctic cloudy boundary layer, Q. J. Roy. Meteor. Soc., 114, 715-746, 1988.

Curry, J. A., Randall, D., Rossow, W. B., and Schramm, J. L.: Overview of arctic cloud and radiation characteristics, J. Climate, 9, 1731-1764, 1996.

Curry, J. A., Hobbs, P. V., King, M. D., Randall, D. A., Minnis, P., Isaac, G. A., Pinto, J. O., Uttal, T., Bucholtz, A., Cripe, D. G., Gerber, H., Fairall, C. W., Garrett, T. J., Hudson, J., Intrieri, J. M., Jakob, C., Jensen, T., Lawson, P., Marcotte, D., Nguyen, L., Pilewskie, P., Rangno, A., Rogers, D. C., Strawbridge, K. B., 
Valero, F. P. J., Williams, A. G., and Wylie, D.: FIRE Arctic Clouds Experiment, B. Am. Meteorol. Soc., 81, 5-30, 2000.

Deardorff, J. W.: Prediction of convective mixed-layer entrainment for realistic capping inversion structure, J. Atmos. Sci., 36, 424436, 1979.

Deardorff, J. W.: Cloud top entrainment instability, J. Atmos. Sci., 37, 131-147, 1980.

Dyer, A. J. and Hicks, B. B.: Flux-gradient relationships in the constant flux layer, Q. J. Roy. Meteor. Soc., 96, 715-721, 1970.

Fridlind, A. M., van Diedenhoven, B., Ackerman, A. S., Avramov, A., Mrowiec, A., Morrison, H., Zuidema, P., and Shupe, M. D.: A FIRE-ACE/SHEBA case study of mixed-phase Arctic boundary-layer clouds: Entrainment rate limitations on rapid primary ice nucleation processes, J. Atmos. Sci., accepted, doi:10.1175/JAS-D-11-052.1, 2011.

Garratt, J. R.: The Atmospheric Boundary Layer, Cambridge University Press, UK, 316 pp., 1992.

Harrington, J., Reisin, T., Cotton, W. R., and Kreidenweis, S. M.: Exploratory cloud resolving simulations of boundary layer Arctic stratus: Part II: Transition-season clouds, Atmos. Res., 51, 45-75, doi:10.1016/S0169-8095(98)00098-2, 1999.

Hong, S.-Y., Noh, Y., and Dudhia, J.: A new vertical diffusion package with an explicit treatment of entrainment processes, Mon. Weather Rev., 134, 2318-2341, 2006.

Jiang, H. J., Feingold, G., Cotton, W. R., and Duynkerke, P. G.: Large-eddy simulations of entrainment of cloud condensation nuclei into the Arctic boundary layer: May 18, 1998, FIRE/SHEBA case study,. J. Geophys. Res., 106, 1511315122, 2001.

Klein, S. A., McCoy, R., Morrison, H., Ackerman, A., Avramov, A., de Boer, G., Chen, M., Cole, J., DelGenio, A. D., Falk, M., Foster, M., Fridlind, A., Golaz, J.-C., Hashino, T., Harrington, J., Hoose, C., Khairoutdinov, M., Larson, V., Liu, X., Luo, Y., McFarquhar, G., Menon, S., Neggers, R., Park, S., von Salzen, K., Schmidt, J. M., Sednev, I., Shipway, B., Shupe, M., Spangenberg, D., Sud, Y., Turner, D., Veron, D., Walker, G., Wang, Z., Wolf, A., Xie, S., Xu, K.-M., Yang, G., and Zhang, G.: Intercomparison of model simulations of mixed-phase clouds observed during the ARM Mixed-Phase Arctic Cloud Experiment. I: Single-layer cloud, Q. J. Roy. Meteor. Soc., 135, 979-1002, 2009.

McFarquhar, G. M., Ghan, S., Verlinde, J., Korolev, A., Strapp, J. W., Schmid, B., Tomlinson, J. M., Wolde, M., Brooks, S. D., Cziczo, D., Dubey, M. K., Fan, J., Flynn, C., Gultepe, I., Hubbe, J., Gilles, M. K., Laskin, A., Lawson, P., Leaitch, W. R., Liu, P., Liu, X., Lubin, D., Mazzoleni, C., Macdonald, A.-M., Moffet, R. C., Morrison, H., Ovchinnikov, M., Shupe, M. D., Turner, D. D., Xie, S., Zelenyuk, A., Bae, K., Freer, M., and Glen, A.: Indirect and Semi-Direct Aerosol Campaign (ISDAC): The Impact of Arctic Aerosols on Clouds, B. Am. Meteorol. Soc., 92, 183-201, doi:10.1175/2010BAMS2935.1, 2011.

Morrison, H. and Pinto, J. O.: Mesoscale modeling of springtime Arctic mixed-phase stratiform clouds using a new two-moment bulk microphysics scheme, J. Atmos. Sci., 62, 3683-3704, 2005.

Morrison, H. and Pinto, J. O.: Intercomparison of bulk cloud microphysics schemes in mesoscale simulations of springtime Arctic mixed-phase stratiform clouds, Mon. Weather Rev., 134, 18801900, 2006.

Morrison, H., Pinto, J. O., Curry, J. A., and McFarquhar,
G. M.: Sensitivity of modeled arctic mixed-phase stratocumulus to cloud condensation and ice nuclei over regionally varying surface conditions, J. Geophys. Res., 113, D05203, doi:10.1029/2007JD008729, 2008.

Morrison, H., Thompson, G., and Tatarskii, V.: Impact of Cloud Microphysics on the Development of Trailing Stratiform Precipitation in a Simulated Squall Line: Comparison of One- and Two-Moment Schemes, Mon. Weather Rev., 137, 991-1007, doi:10.1175/2008MWR2556.1, 2009.

Morrison, H., Zuidema, P., Ackerman, A. S., Avramov, A., de Boer, G., Fan, J., Fridlind, A. M., Hashino, T., Harrington, J. Y., Luo, Y., Mikhail Ovchinnikov, M., and Shipway, B.: Intercomparison of cloud model simulations of Arctic mixed-phase boundary layer clouds observed during SHEBA, J. Adv. Mod. Earth Systems, 3, M06003, http://www.agu.org/journals/ms/, 2011.

Nicholls, S.: The dynamics of stratocumulus: Aircraft observations and comparisons with a mixed layer model, Q. J. Roy. Meteor. Soc., 110, 783-820, 1984.

Norris, J. R.: Low cloud type over the ocean from surface observations. Part I: Relationship to surface meteorology and the vertical distribution of temperature and moisture, J. Climate, 11, 369382, 1998.

Paulson, C. A.: The mathematical representation of wind speed and temperature profiles in the unstable atmospheric surface layer, J. Appl. Meteor., 9, 857-861, 1970.

Pinto, J. O.: Autumnal mixed-phase cloudy boundary layers in the Arctic, J. Atmos. Sci., 55, 2016-2038. doi:10.1175/1520-

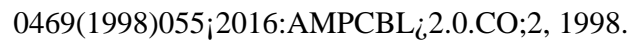

Prenni, A. J., Harrington, J. Y., Tjernström, M., DeMott, P. J., Avramov, A., Long, C. N., Kreidenweis, S. M., Olsson, P. Q., and Verlinde, J.: Can ice-nucleating aerosols affect Arctic seasonal climate?, B. Am. Meteorol. Soc., 88, 541-550, 2007.

Randall, D. A.: Conditional instability of the first kind upsidedown, J. Atmos. Sci., 37, 125-130, 1980.

Sedlar, J. and Tjernström, M.: Stratiform cloud-inversion characterization during the Arctic melt season, Bound.-Lay. Meteorol. 132, 455-474, 2009.

Sedlar, J., Shupe, M. D., and Tjernström, M.: On the relationship between thermodynamic structure and cloud top, and its climate significance in the Arctic, J. Climate, under review, 2011.

Shupe, M. D.: A ground-based multiple remote-sensor cloud phase classifier, Geophys. Res. Lett., 34, L2209, doi:10.1029/2007GL031008, 2007.

Shupe, M. D.: Clouds at Arctic Atmospheric Observatories, Part II: Thermodynamic phase characteristicsm, J. Appl. Meteor. Clim., 50, 645-661, 2011.

Shupe, M. D., Matrosov, S. Y., and Uttal, T.: Arctic mixed-phase cloud properties derived from surface-based sensors at SHEBA, J. Atmos. Sci., 63, 697-711, 2006.

Shupe, M. D., Kollias, P., Poellot, M., and Eloranta, E.: On deriving vertical air motions from cloud radar Doppler spectra, J. Atmos. Ocean. Tech., 25, 547-557, 2008a.

Shupe, M. D., Kollias, P., Persson, P. O. G., and McFarquhar, G. M.: Vertical motions in Arctic mixed-phase stratiform clouds. J. Atmos. Sci., 65, 1304-1322, 2008b.

Solomon, A., Morrison, H., Persson, O., Shupe, M., and Bao, J.-W.: Investigations of microphysical parameterizations of snow and ice in Arctic clouds during M-PACE through model-observations comparison, Mon. Weather Rev., 137, 3110-3128, 2009. 
Skamarock, W. C., Klemp, J. B., Dudhia, J., Gill, D. O., Barker, D. M., Duda, M. G., Huang, X.-Y., Wang, W., and Powers, J. G.: A description of the Advanced Research WRF version 3. NCAR Tech. Note NCAR/TN-475+STR, 113 pp., 2008.

Stevens, B., Cotton, W. R., Feingold, G., and Moeng, C.H.: Large-eddy simulations of strongly precipitating, shallow, stratocumulus-topped boundary layers, J. Atmos. Sci., 55, 36163638, 1998.

Tjernström, M., Leck, C., Persson, P. O. G., Jensen, M. L., Oncley, S. P., and Targino, A.: The summertime Arctic atmosphere: meteorological measurements during the Arctic Ocean Experiment 2001, B. Am. Meteorol. Soc., 85, 1305-1321, 2004.

Turner, D. D., Clough, S. A., Liljegren, J. C., Clothiaux, E. E., Cady-Pereira, K., and Gaustad, K. L.: Retrieving precipitable water vapor and liquid water path from Atmospheric Radiation Measurement (ARM) program's microwave radiometers, IEEE T. Geosci. Remote, 45, 3680-3690, 2007.
Webb, E. K.: Profile relationships: The log-linear range, and extension to strong stability, Q. J. Roy. Meteor. Soc., 96, 67-90, 1970.

Wood, R. and Bretherton, C. S.: Boundary layer depth, entrainment, and decoupling in the cloud-capped subtropical and tropical marine boundary layer, J. Climate, 17, 3576-3588, 2004.

Wyant, M. C., Bretherton, C. S., Rand, H. A., and Stevens, D. E.: Numerical simulations and a conceptual model of the stratocumulus to trade cumulus transition, J. Atmos. Sci., 54, 168-192, 1997.

Zhang, D.-L. and Anthes, R. A.: A high-resolution model of the planetary boundary layer-sensitivity tests and comparisons with SESAME-79 data, J. Appl. Meteor., 21, 1594-1609, 1982.

Zhu, P., Albrecht, B. A., Ghate, V. P., and Zhu, Z.: Multiplescale simulations of stratocumulus clouds, J. Geophys. Res., 115, D23201, doi:10.1029/2010JD014400, 2010. 